\title{
25 Research Square \\ Amplified Risk of Compound Heat Stress-Dry Spells in Urban India
}

Poulomi Ganguli ( $\sim$ pganguli@agfe.iitkgp.ac.in )

Indian Institute of Technology Kharagpur https://orcid.org/0000-0002-2372-1121

\section{Research Article}

Keywords: Amplified Risk, Compound Heat, stress-Dry Spells, Urban India, warm-dry, extreme temperature or low precipitation, severe heatwave

Posted Date: September 28th, 2021

DOl: https://doi.org/10.21203/rs.3.rs-748914/v1

License: (9) This work is licensed under a Creative Commons Attribution 4.0 International License. Read Full License 


\section{Amplified Risk of Compound Heat stress-Dry Spells in Urban India}

2 Poulomi Ganguli ${ }^{1}$

$3{ }^{1}$ Agricultural and Food Engineering Department, Indian Institute of Technology Kharagpur, 4 India

5

$6 \quad$ *Corresponding author: P. Ganguli (pganguli@agfe.iitkgp.ac.in)

Key Points:

- A multivariate perspective is highlighted to assess compound heat stress-dry spell potentials over 23 urban locations in India

- Spatial coherence in average timing of extreme temperature and presence of four distinct zones based on seasonality

- A median 6-fold amplification in compound heat stress-dry spell than accounting expected annual number of 50-year heatwave events 


\section{Abstract}

44 Compound warm-dry spells over land, which is expected to occur more frequently and expected to cover a much larger spatial extent in a warming climate, result from the simultaneous or successive occurrence of extreme heatwaves, low precipitation, and synoptic conditions, e.g., low surface wind speeds. While changing patterns of weather and climate extremes cannot be ameliorated, effective mitigation requires an understanding of the multivariate nature of interacting drivers that influence the occurrence frequency and predictability of these extremes. However, risk assessments are often focused on univariate statistics, incorporating either extreme temperature or low precipitation; or at the most bivariate statistics considering concurrence of temperature versus precipitation, without accounting for synoptic conditions influencing their joint dependency. Based on station-based daily meteorological records from 23 urban and peri-urban locations of India, covering the 19702018 period, this study identifies four distinct regions that show temporal clustering of the timing of heatwaves. Further, combining joint probability distributions of interacting drivers, this analysis explored compound warm-dry potentials that result from the co-occurrence of warmer temperature, scarcer precipitation, and synoptic wind patterns. The results reveal a 50year severe heat stress tends to be more frequent and is expected to become 5 to 17-year events at each location. Notably, considering dependence among drivers, a median 6-fold amplification (ranging from 3 to 10-fold) in compound warm-dry spell frequency is apparent relative to the expected annual number of a local 50-year severe heatwave episode, indicating warming-induced desiccation is already underway over most of the urbanized areas of the country.

\section{Introduction}

Compound warm-dry spells, i.e., simultaneous or temporal clustering of heat stress (or temperature extreme) and dry spells (results from precipitation deficit), would result in extreme impacts in terms of agricultural losses, habitat mortality, scarcity in available water for energy and food production (Miralles et al. 2019). A prolonged dry spell result in a meteorological drought (Pérez-Sánchez and Senent-Aparicio 2018). Drought and heatwaves continue to be the deadliest natural hazards, especially when hot and dry conditions co-occur and have caused high mortality rates in India in recent years (Mazdiyasni et al. 2017). While drought occurs due to extreme deficiency of available water leading to a lack of soil moisture replenishment, heatwaves exacerbate the initiation and severity of a drought episode with increased surface temperature, low wind speed, and/or increased evapotranspiration (Basara et al., 2019; Teuling et al., 2013; Diffenbaugh et al., 2015; Hassan and Nayak, 2020). On the other hand, prolonged dry conditions often lead to dry soil conditions, which may increase the latent and sensible heat fluxes, leading to amplified extreme temperature and persistent heat stress events (Dai 2011; Manning et al. 2018). 
In India, drought occurs due to delayed onset and/or early retreat of south-west monsoon or a partial or complete failure of the monsoon rainfall (Van Loon 2015). Indian subcontinent experiences summer (pre-monsoon) from March to May and most of the landmass remains under extreme temperature during May owing to direct solar heating from transiting Sun towards the north, with accumulated heat evolving from the desert in the northwest part, and physiography of central plateau and the northern plains of the country (Satyanarayana and Rao 2020). In many parts of the country, heatwaves last longer than usual due to delayed arrival of seasonal monsoon (June - September is considered as monsoon season in the Indian subcontinent), leading to dry spells, compounding the overall impact on water and food security as well as environmental sustainability (Bandyopadhyay et al. 2016). Warmer temperature increases evaporative demand, together with concurrent shifts in precipitation owing to climate change consequences, amplifying compound warm and dry conditions (Im et al. 2017; Mora et al. 2018; Sato and Nakamura 2019). Quantifying heatwave-induced dry-spell is challenging given complex interdependence between various drivers, estimating event probabilities even more difficult and complex.

Urban and peri-urban populations are typically exposed to heatwaves, which are often exacerbated by the urban heat island effects (Yang et al. 2017; Shastri et al. 2017). Extreme heatwave conditions induce additional challenges to individuals and health professionals in the management of the COVID-19 pandemic by endangering the lives and health of people in densely populated urbanized settings. Further, personal protective equipment (PPE) used by health care professionals makes it very difficult to lose body heat and heat stress can increase with consecutive days of exposure to a warming climate (Golechha and Panigrahy 2020). In recent decades, India has witnessed unprecedented growth in urban population with a nearly doubled level of urbanization since the 1950s and reported around 461 million urban dwellers in 2018 (UN DESA, 2018). Further, intensive urbanization stresses urban watersheds by increasing water demand for energy, agricultural and urban sectors and may lead to changes in regional hydro-meteorology affecting changes in the space-time dynamics of precipitation (Singh et al. 2016; Liu and Niyogi 2019). Although individual drivers, heat stress and deficit precipitation may not extreme in isolation, their large consecutive and/or concurrent exceedances can lead to extreme flash droughts leading to "Thirsty cities" (Kumar 2014), causing serious economic and societal consequences.

The review of the literature shows most of the studies investigate either heatwaves (Basara et al., 2010; Habeeb et al., 2015; Lemonsu et al., 2015; Im et al., 2017; Matthews et al., 2017; Yang et al., 2019; Jacobs et al., 2019; Perkins-Kirkpatrick and Lewis, 2020; Satyanarayana and Rao, 2020) or dry spells and meteorological droughts (Duffy et al. 2015; Huang et al. 2017; Shiru et al. 2019) independently and in few cases interdependencies among different features of each of these drivers (Mirakbari et al. 2010; Masud et al. 2015; Ganguli and Ganguly 2016; Mazdiyasni et al. 2019). Although there is no universal definitions exist, most of the studies 
define heat stress events based on a meteorologically motivated index, such as daily maximum temperature (Basara et al., 2010; Habeeb et al., 2015; Lemonsu et al., 2015; Yang et al., 2019; Perkins-Kirkpatrick and Lewis, 2020) and/or relative humidity (Matthews et al., 2017) exceeds a certain threshold value over a consecutive period of days. However, the current thresholdbased univariate indices often underestimate the impact since they fail to characterize the concurrence of interdependent drivers, which can further exacerbate the associated hazard (e.g., concurrence of heatwave, short/long-term precipitation deficit and synoptic circulations) (Leonard et al. 2014).

Concurrent analysis of hot and dry conditions constituting multivariate compound extremes (Ridder et al., 2020) has received significant attention in recent decades (AghaKouchak et al., 2014; Hao et al., 2018; Koster et al., 2009; Sharma and Mujumdar, 2017; Zscheischler and Seneviratne, 2017; Ridder et al., 2020). Miralles et al. (2019) have shown the relationship between heatwaves and dry spells in the United States (US) during the 2012-13 Midwestern drought, which led to an 'exceptional drought' condition according to the US Drought Monitor. Using high-resolution gridded daily rainfall and temperature records, Sharma and Mujumdar (2017) investigated observed changes in frequency and spatial extent of concurrent meteorological droughts (results from prolonged dry spell owing to precipitation deficit) and heatwaves defined at different threshold levels during 1951-1980 versus 1981-2010 time windows over meteorologically homogeneous regions of India. Their analysis showed a substantial increase in the frequency and spatial extent of concurrent heatwaves and meteorological droughts across India with a shift in spatial extent in the post-1980s as compared to the pre-1980s era. However, their analysis was limited to grid-based observations considering only two drivers, high temperature and low precipitation to define concurrent events. Although the station-based record has certain inherent unobserved biases (for example, biases due to observational procedures or instrumentation type), the primary strength of ground-based observation is its ability to rigorously capture local conditions, whereas interpolated gridded dataset often underestimates inter-annual variability and magnitude of extremes - especially in areas with low station density (Mannshardt-Shamseldin et al. 2010; King et al. 2013; Raymond et al. 2020). Using coarse resolution $\left(2.5^{\circ} \times 2.5^{\circ}\right)$ global land-based gridded observation as well as re-analysis dataset, recently, Ridder et al. (2020) have shown the global hotspots of joint occurrence of bivariate hazards, such as heatwaves - low precipitation, and wind - drought pairs (see Fig. 1 in Ridder et al. 2020). However, the analysis was limited to a bivariate hazard modelling without considering the concurrence of more than two drivers simultaneously. Further, the coarser resolution of the dataset may be inadequate to represent the pronounced local-scale variability, leading to underestimation of extreme weather features. Using wet-bulb temperature, Raymond et al. (2020) have shown that humid heat is highly localized in space and time, which is substantially underestimated in gridded re-analysis products relative to station-based observations. Using ground-based monthly rainfall and temperature records of 30-years (1981-2010), one pioneering study (Bandyopadhyay et al., 
2016), hereafter 'BAN16', investigating the temperature-precipitation interactions in the state of Gujarat, India revealed a causal connection between heatwaves and dry spells. Their study unveiled an indirect influence of heatwaves and temperature extremes on meteorological drought development and further intensification. However, whether obtained insights are generalizable for other climatic regions of India with distinct hydroclimatological conditions remains unknown.

Although several studies have shown interdependence between temperature and precipitation in modulating heatwave-induced compound dry spells and meteorological droughts (AghaKouchak et al., 2014; Diffenbaugh et al., 2015; Hao et al., 2018; Sharma and Mujumdar, 2017), little attention has been paid to relate the effects of synoptic conditions, for example, low surface winds in impacting the relation between heatwaves and dry-spells, which triggers meteorological drought development. The Studies based on observations (Roderick et al. 2009) and detailed physical modeling (Jiménez et al. 2011) have shown that surface wind speed controls the evaporative demand, and hence, drought mechanisms. Using a Lagrangian heattracking model, (Schumacher et al. 2019) have shown the role of upwind land-atmospheric feedbacks in amplification of the two pan-European mega-heatwave events (2003 and 2010) and corresponding dry spells. Anomalous Dry-and-warm air advect the sensible heat, which comes in torrents, leading to an abrupt increase in air temperatures that further strengthen the local land-atmosphere feedback via soil desiccation (Refer Figure 3 in Schumacher et al., 2019). In particular, in urban areas, the urban heat island effect tends to intensify due to insufficient soil moisture (because of precipitation deficit) and low wind speed during the heatwave (Dong et al., 2018; Li et al., 2019). Hence, the drivers of the compound warm-anddry spell would be temperature extreme, low wind speed, and precipitation deficits, which in turn, are driven by a range of processes such as land-atmospheric feedback (Miralles et al. 2019).

Urban and peri-urban areas in South Asia are likely to experience severe water scarcity due to increased economic activity and water demand because of increased population and climate variability (Schewe et al. 2014; Schiermeier 2014). Among the 27 Asian cities with a population of over one million, the two of the Indian cities, Delhi and Chennai in India, were identified as the worst affected cities in terms of per capita water availability (Ray and Shaw 2019). While most of the studies explored the potential of compound warm-dry spells across the global (Ridder et al., 2020; Hao et al., 2018; Zscheischler and Seneviratne, 2017), continental or national scales (AghaKouchak et al., 2014; Diffenbaugh et al., 2015; Sharma and Mujumdar, 2017), little is known about the compounding roles of heat stress-low precipitation-and synoptic low wind speeds in modulating multi-hazard event over the densely populated cities of urban India. Considering 23 major urban habitats (Fig. 1; Table S1) located across different hydroclimatologically homogeneous regions of India, I aim to address the following research questions: (i) To what extent each of the interrelated hydroclimatic variables 
contributes to compound warm-and-dry spells? (ii) Does the apparent nonstationarity among interacting drivers impact the occurrence frequency of multi-hazard events, and (iii) how severe would be the compound hazard-potential from associated drivers as compared to the univariate hazard solely considering heatwaves? This paper builds on BAN16 analysis of temperature extremes and dry spells and investigate the associated severity over cities of India that are located in six homogeneous monsoon sub-regions (Figure 1). To the author's knowledge, so far no comprehensive analysis on temperature extremes and/or concurrence of high temperature, low wind speeds and rainfall deficit over urban habitats located in these subregions is available and hence considered in this study. The obtained insights would add value in the issuance of alerts that can help the community to better prepare and lessen the impacts of compound warm-dry events, and devise adaptation strategies in the situation of warmer temperature and scarcer available water.

\section{Data and Methodology}

\subsection{Hydrometeorological Forcing}

Based on record availability, the station-based daily maximum and minimum dry-bulb temperature $\left({ }^{\circ} \mathrm{C}\right)$, average wind speed $\left(\mathrm{kmh}^{-1}\right)$, and rainfall $(\mathrm{mm})$ of 23 cities are collected from the India Meteorological Department for the time-period range between 1970 and 2018. These cities are located over six homogeneous monsoon regions of India with population distribution varies from 0.099 to 16.43 Million (Figures. 1a-b and Table S1), out of which Panjim (in the state of Goa) being the least populated and Mumbai (in the state of Maharashtra) has the highest population. Based on coherent rainfall and regional circulation pattern, these six homogeneous monsoon sub-regions are defined by the Indian Institute of Tropical Meteorology (IITM), Pune, India (www.tropmet.res.in).

\subsection{Heat Stress Characterization and it's Time Evolution}

Following earlier studies (Lemonsu et al., 2015; Yang et al., 2019; Perkins-Kirkpatrick and Lewis, 2020), this study defines extremes in dry-bulb temperature as a measure of heat stress event. The heatwave Intensity (hereafter HWI), is calculated as the average of the daily mean temperature over the 10-day time window i.e., from $t=-2$ to 7-day of the occurrence of the annual maxima daily temperature (Weiss and Hays 2005). Following Mazdiyasni et al. (2019), mean daily maxima temperature is considered to account for the night-time temperature since the cumulative impacts of high temperatures (i.e., night-time high temperature during a heatwave) can have a deadly impact on human health. Further, the definition of heatwaves as adopted here and also followed elsewhere (Mazdiyasni et al., 2019; Ouarda \& Charron, 2018; Saeed et al., 2021), allows modeling of annual occurrence probability of consecutive warm days and resulting dry spells associated with this event. While subjective, the choice of the 2 to 10-day time window for analyzing heat stress, is typically followed in the literature (Khaliq et al. 2005; Mazdiyasni et al. 2019; Harrington et al. 2019). Recently, Harrington et al. (2019) 
have chosen a continuous 12-day period in the middle of the summer to define the " 1947 heatwave' over central Europe during which temperature was found to be persistently high with a similar circulation state throughout. Further, in south Asia, atmospheric patterns during heatwaves are often linked to large-scale blocking in mid-latitudes that may persist several consecutive days to weeks ( $\mathrm{Li}$ et al. 2019; Min et al. 2020), which justifies our choice of a 10day time window to define the evolution of heatwaves. Figures 2 and S1 illustrate definition sketch of heatwave intensity during the 2010's heatwave event for Ahmedabad and Guwahati, the two climatologically dissimilar regions. Following this definition, HWI for each year (i.e., one sample per year) is sampled for all 23 urban sites.

Since the timing and intensity of heatwaves and associated dry spells affect the vegetative response, especially during growth stages, the occurrence time of extreme temperature is investigated. The average timing of the occurrence of annual maximum temperature is determined using the directional statistics, in which the occurrence day of the annual maxima daily mean temperature is converted to an angular value (Laaha and Blöschl, 2006; see Supporting Information, SI S1.1). Finally, to make trend estimates from different climates as well as different sample lengths comparable, the percentage change per decade (i.e., 10 years) is calculated for each urban sites (Gudmundsson et al., 2018)

$T_{s}=\frac{\tau_{H W I} \times 10 \text { years }}{\bar{x}_{H W I}} \times 100$

Where $T_{s}$ is the trend at a station location with the unit as a percentage change per decade. $T_{s}$ is computed using Theil-Sen slope estimator, $\tau_{H W I} ; \bar{x}_{H W I}$ is the mean of the HWI time series for a given location. Statistical significance of decadal changes in HWI is determined using the nonparametric Mann-Kendall trend test with a correction for ties and autocorrelation in the time series (Reddy and Ganguli 2013). To increase the statistical power of the test, results of the statistical significance are reported at a $10 \%$ significance level (Wasserstein and Lazar 2016) throughout the manuscript.

\subsection{Compound Event Delineation}

The compound warm-dry spell is defined when annual maxima daily temperature coincides with below-seasonal mean accumulated precipitation (as an indication of precipitation deficit), and the minimum wind speed (to indicate low wind speed) of the affected stations during a time window of two days prior and seven days after the occurrence of the extreme temperature event for each calendar year. Subsequently, for a station, if a particular year shows aboveaverage rainfall during the time windows surrounding annual maxima temperature, that particular event combination is discarded from the time series to ensure a credible sampling of dry events and the resulting compounding extremes. Here below-average precipitation is determined from the baseline seasonal climatology, beginning in May 1970 to September 1999 (i.e., over 30-year) in which values are calculated for the March-May, 3-month average rainfall 
when at a particular year heatwave day occurs in the "summer", and for June-September, 4month average rainfall when heatwave days occur during "monsoon" season. Following this definition, the concurrence of heat stress, below-average accumulated precipitation (as a proxy for dry spells) preceded and/or coincided by low wind speed over the same geographical region within a week of occurrence of the temperature extreme, can be categorized as "preconditioned" and "multivariate" compound extremes (Zscheischler et al. 2020). While associated drivers, low wind speed and below average precipitation, both in isolation, may not have a significant impact, their coincidence or successive occurrences within a limited time window in combination with heat stress events may exacerbate the impact of heat stress, for example, adverse effect on crop growth and development (Luan and Vico 2021), critical infrastructure failures (Turner et al. 2021), and impacting green-blue infrastructure of urban space. The use of a time window enables lagged responses for other hydroclimatic variables since extremes may not occur on the same day (Rowe and Villarini 2013; Czajkowski et al. 2017; Berghuijs et al. 2019; Kemter et al. 2020).

\subsection{Modelling of Compound Heat Stress-Dry Spell Drivers}

Since the review of the literature shows dependence strength among drivers largely controls the occurrence frequency of compound extremes (Zscheischler and Seneviratne 2017), first, the dependence strengths between pairs of drivers, $(i)$ heatwave severity versus low wind speed, (ii) precipitation deficit during heatwave episode versus low wind speed, and (iii) heatwave severity versus (below-average) accumulated precipitation pairs are determined using the complete as well as extremal dependence measures. While complete dependence is analyzed using nonparametric Kendall's $\tau$, the extremal dependence is determined using empirical (rank-based) CFG upper as well as lower tail dependence metrics, $\lambda_{C F G}^{U}$ and $\lambda_{C F G}^{L}$ (Poulin et al. 2007), respectively (see SI 1.2). Further, the statistical significance of dependence strength is determined by simulating 10000 random bootstrap samples and calculating the $p$ value (i.e., probability of observing a stronger correlation by chance) of the test.

Since low wind speed often contains tied values, following earlier studies (McGee 2018), a small amount of random noise ranging between 0.001 and 0.0001 is added to the original record to make the values distinct while ensuring without being adjusted for tied ranks. Likewise, heat stress typically occurred during the summer, which is accompanied by days with no or zero rainfall values in the accumulated precipitation time series resulting in a tied value, which may impact the estimation of ranks. Hence, to overcome the effect of tied observations while ensuring a little to no shift in the distributional properties of the series, a similar treatment is followed for the accumulated precipitation time series containing more than $20 \%$ zeroes.

Next, the presence of monotonic trends in each hydrometeorological time series is investigated using the non-parametric rank-based Mann-Kendall (MK) test with correction for ties and autocorrelations (Reddy and Ganguli 2013). For modelling heatwave intensity and wind speed, 
the application of extreme value theory is followed, which is based on block maxima approach (see SI 1.3). On detection of a significant trend in heatwaves and low wind speed (Table S2), the marginal distribution of interdependent drivers are modelled using Generalized Extreme Value (GEV) distribution (Coles et al. 2001) with a nonstationary assumption (Hundecha et al., 2008; Cheng et al., 2014; Mazdiyasni et al., 2019; Ouarda \& Charron, 2018). If no trend is detected, the series is modelled with a stationary GEV distribution (Cheng et al., 2014).

Since the presence of monotonic trend in the time series infers a "Shifted Mean" condition (i.e., an increase in the probability distribution) (Ye and Fetzer 2019), if the trend in the time series is found to be significant, then the location parameter of the GEV distribution, $\mu$ is modelled assuming a linear function of time (Katz 2013; Cheng et al. 2014), while scale and shape parameters are assumed to be time-invariant.

$\tilde{\mu}=\mu(t)=\mu_{0}+\mu_{1} t, t=1,2, \ldots, n$

Here, $t$ indicates the year over which extremes are sampled. The parameter $\mu_{1}$ indicates the slope of a linear trend in the centre of the distribution and $\mu_{0}$ is the intercept. For the nonstationary GEV model, the classical GEV model (Eq. S8 in SI 1.3) is modified as a linear trend in the location parameter, $\tilde{\mu}$ but no trend in scale and the shape parameters.

Since the maximum likelihood-based estimator in small sample sizes $(n \leq 50)$, often leads to an unrealistic value of the shape parameter of the GEV distribution (Martins and Stedinger 2000), the parameters of the distribution is obtained via Bayesian inference combined with Differential Evaluation Markov Chain Monte Carlo (DE-MC) simulation (Cheng et al. 2014). The priors for the location and scale parameters are non-informative normal distributions, whereas following the literature (Renard et al. 2013), the prior for the shape parameter is chosen as a normal distribution with a standard deviation of 0.3 . The simulations are run for 3000 iterations of five parallel chains, and 2001-3000 iterations of each chain is kept as a post-burn in simulated draws. Finally, parameters of GEV distribution is derived by computing the $50^{\text {th }}$ percentile of the post-burn in random draws from the posterior distribution. The convergence of DE-MC simulation is checked using a scale-reduction factor as described in (Cheng et al. 2014).

Since for stations across central India, the timing of heatwaves is mostly clustered around the pre-monsoon (April - May) period, the accumulated precipitation value during specified time window may be zero with no precipitation. In such cases, a mixture distribution is employed to take into account the zero and non-zero parts of the precipitation, in which the non-zero portion of the precipitation amount is modelled using a series of distributions (Wan et al. 2005), such as 2-parameter log-normal (characterized by location and scale parameters), log-logistic (characterized by scale and shape parameters), and the 2-parameter Gamma (characterized by 
location and scale parameters), and the stationary and the nonstationary forms of GEV distributions depending on the nature of (insignificant/significant) trends in the time series. The CDF of the mixed distribution function is derived as (Haan 1977)

$F_{X}(x)=q+(1-q) G_{X}(x)$

Where, $q$ is the zero precipitation probability and $G_{X}(x)$ is the CDF estimated for nonzero precipitation. While the goodness of fit of the fitted GEV distributions is assessed using the Kolmogorov-Smirnov goodness of fit test, the performance of the mixture distributions is assessed following Akaike Information Criteria (AIC) considering small sample correction (Burnham and Anderson, 2003).

Tables S3-S4 show the goodness-of-fit of the GEV distributions in modelling HWI and average wind speed respectively. For HWI, all sites, passes the KS-test at a 10\% significance level, as indicated from the high p-value of the test. On the other hand, for low wind speeds, all sites except, Dehradun, Hissar and Guwahati pass the KS-test at a $10 \%$ significance level. For these sites, the p-value is relatively less and ranges between 0.001 and 0.05 , which is greater than zero. Table S5 presents comparative results of AIC statistics achieved by different parametric distributions for modelling non-zero part of the precipitation across all urban sites; which suggests a majority of sites are modelled by Gamma (over 78\%; 18 out of 23) distributions and the rest using log-logistic and stationary form of GEV (2\% each) distributions, respectively. In none of the stations, a nonstationary form of GEV distribution provides reasonable estimates for modelling non-zero precipitation, therefore, was not considered in the subsequent analysis. Since precipitation intensity and dry-wet spells over global tropical regimes tend to follow Gamma distribution (Martinez-Villalobos and Neelin 2019), the choice of Gamma probability distribution to model accumulated precipitation is reasonable in this case. Finally, the marginal distribution fit of each driver is assessed by comparing the CDF of empirical distributions against the CDF of the best fitted theoretical distributions (Figures S2-S4), which suggest a satisfactory fit of the theoretical distributions.

\subsection{Compound Hazard Analysis using Multivariate Statistics}

Next, the trivariate dependence between concurrent drought drivers (i.e., three pair-wise dependent variables) is modelled using copula-based multivariate distribution (Sklar 1973). Although Archimedean copulas perform reasonably well in modelling bivariate dependencies of hydroclimatic extremes because of their several desirable properties, such as analytical tractability and associativity (Ganguli and Reddy 2012), their extension to a higher dimension is limited since lower-level dependencies cannot be preserved credibly. For instance, multivariate $n$ - Archimedean copulas with a symmetric structure can model only positive dependence (Grimaldi and Serinaldi, 2006). On the other hand, multivariate $n$ - Archimedean 
401

402

403

404

405

406

407

408

409

410

411

412

413

414

415

416

417

418

419

420

421

422

423

424

425

426

427

428

429

430

431

432

433

434

435

copulas with an asymmetric structure (Ribeiro et al. 2020) has limitations that weak dependences are averaged in the asymmetric multivariate and that there is a restriction in its application as the correlation between two pairs should be identical and lower than the third pair.

Metaelliptical families of Student's $t$ copulas do not suffer from such limitations and allows for modelling of joint fat tails that enables an increased probability of joint extremes while ensuring credible estimates of risk (Nguyen et al. 2020). To estimate parameters of Student's $t$ copula, a two-step estimation procedure is followed (Zeevi and Mashal 2002): first, from the correlation matrix, nonparametric rank-based pair-wise Kendall's tau $(\tau)$ dependence is estimated following the method of moments based approach and then following the maximum pseudo-likelihood procedure, the number of degrees of freedom parameter of Student's $t$ copula is estimated. To avoid trapping into a local optimum, with gradient-based search technique, for maximization purpose a real-coded genetic algorithm (GA) is employed for estimating the degrees of freedom parameter of Student's $t$ copula (Janga Reddy and Ganguli 2012). Following Genest et al., 2009, the goodness-of-fit of the trivariate copula-based model is assessed using a parametric bootstrap-based approach for the distance-based Cramer von Mises distance (i.e., integrated squared difference between empirical and parametric copula distributions(Genest et al. 2009) statistics. Accounting tradeoffs between computational complexity as well as the time response, $N=250$ bootstrap replications are considered and pvalues of the fitted copula models are obtained (Table S6).

The degree of freedom of the fitted Student's $t$ copula varies from 2 to 10 for each site. The spatial distribution of the degree of freedom parameters (Figure S5; Table S6) shows a spatial clustering of higher degrees of freedom for the majority of cities across coasts, indicating tail of the distributions for these areas is relatively lighter; whereas the cities away from coasts, especially at interior locations show lower degrees of freedom values indicating fatter tail behavior. The spatial distribution of the p-values of the fitted trivariate student's $t$ copula shows (Figure S5; Table S6) greater than zero values across all sites, suggesting the trivariate distribution of HWI-low wind-low rainfall could be adequately described by student's $t$ family of copulas with varying degrees of freedom. Further, the credibility of the fitted copula model is evaluated through (i) probability-probability plot of the empirical versus copula-based distribution. The scatter of data points close to the 1:1 line show a good performance of the fitted copula model both at the centre as well as the tails of the distribution (Figure S6). (ii) Comparing the tail dependencies between empirical versus the fitted copula model. For this, the computation of upper and lower tail dependence of bivariate pairs is repeated for $N=1000$ random bootstrap samples simulated from the fitted Student's $t$ copula at each location. Then, the density function of the copula-based simulated random runs with observed tail dependencies is compared (Figure S6). The density functions of bivariate pairs closely 


$$
C D P I=\frac{T_{H W I}}{T_{\text {Compd }}}=\frac{T_{H W I}}{\left(\frac{1}{1-K_{C}\left(\bar{p}_{t}\right)}\right)}
$$

encompass the observed tail dependencies, suggesting a reasonably well fit of the selected copula model in simulating the dependency at extremum tails.

\subsection{Assessing Severity of Heatwave-induced Concurrent Drought Event}

This study proposes a Compound Dry-spell Potential Index (CDPI) suitable for evaluating the impact of compound warm-dry conditions in any location. This index is obtained by comparing the univariate return period to the trivariate joint return period considering co-occurrence or successive occurrence of compound warm-dry drivers. To determine the hazard potential of concurrent events, the quantiles of HWI, low wind speed, and low precipitation correspond to the 50-year severe return level are computed and then the joint return period owing to the concurrence of each driver is investigated. The index is motivated by the amplification factor proposed in (Tebaldi et al. 2012) and later applied in the literature (Buchanan et al. 2017; Ghanbari et al. 2019) that measures the expected frequency of an annual chance of coinciding drivers causing compound warm-dry events. While the previous application of the index was limited to univariate extremes for coastal flood risk assessment under the effect of sea-level rise, in the present study, the applicability of this index is extended to assess spatial variations in multivariate compound warm-dry spell and is defined as

454

455

456

457

458

459

460

461

462

463

464

465

466

467

468

469

Where, $T_{H W I}$ is the univariate frequency of heatwaves correspond to $T=50$-year return period (or an exceedance probability of $2 \%$ ), representing a rare event. The CDPI index is derived from the ratio of at-site $T$-year return period of heatwaves indicating annual exceedance probability of severe heatwave intensity to the copula-based multivariate $T$-year return periods of heatwave-induced compound dry spell. The $C D P I=1$, indicates the perfect agreement between at-site frequency of heatwaves and multivariate frequency involving concurrent drivers. The CDPI value larger (smaller) than 1 indicates amplification (depletion) of heatwave-induced compound dry spell. Based on the available length of records across different sites, the spatial variation of up to 50-year return period events is illustrated, however, the computation of CDPI can be performed for any lower and larger return period events other than the 50 -year event. $T_{\text {Compd }}$ indicates secondary return period as introduced by (Salvadori et al. 2013), $K_{C}(\bullet)$ denotes multivariate Kendall distribution function associated with trivariate copula-based distribution at a critical probability level $\bar{p}_{t}$ (see SI 1.4 for details).

Finally, the compound hazard of heatwave intensity, low wind speed, and low precipitation (within 10-day time window) associated with 50-year severe events are determined using a 
joint survival distribution, (i.e., $\bar{F}(h w i, w, p)=P(H W I>h w i, W>w, P>p)$ assuming their concurrent exceedance of a predefined quantile through 'AND' probability:

$$
\begin{aligned}
\bar{P}_{H W I, W, P} & =P(H W I>h w i, W>w, P>p) \\
= & 1-F_{H W I}(h w i)-F_{W}(w)-F_{P}(p)+ \\
& F_{H W I, W}(h w i, w)+F_{W, P}(w, p)+F_{H W I, P}(h w i, p)-F_{H W I, W, P}(h w i, w, p)
\end{aligned}
$$

where, $F_{H W I}(h w i), F_{W}(w)$ and $F_{P}(p)$ are the marginal distributions of heatwave intensity, low wind speed and precipitation deficit, $F_{H W I, W}(h w i, w), F_{W, P}(w, p), F_{H W I, P}(h w i, p)$ and $F_{H W I, W, P}(h w i, w, p)$ are the bi- and trivariate Kendall distribution functions respectively, obtained numerically from Student's $t$ copula function through $N=10000$ Monte Carlo simulations (SI S1.4). The return level associated with a 50-year event of each of the compound dry spell driver is obtained using empirical Gringorten's plotting position formula (Gringorten 1963), which emphasizes tail probability and is widely being in use for modeling extreme to rare events in the literature (Hao et al. 2018; Chiang et al. 2018).

\section{Results and Discussion}

\subsection{Spatial Coherency in Temporal Evolution of Extreme Temperature}

Figure 2a presents the time series of the anomalously hot summer of 2010 over Ahmedabad city to examine the time-evolution of heatwaves. As discussed in (Azhar et al. 2014), the summer of May 2010 was a period of pronounced heat over a large part of northern and western India claiming significant human mortality and believed to be the hottest summer in the country since records began in late 1800 . The red dashed line in Figure 2a shows the temperature exceeding over $95^{\text {th }}$ percentile $\left(\sim 35^{\circ} \mathrm{C}\right)$ daily temperature for the analysis period, 1970-2017 for the site. Further, a net-zero rainfall was observed during the 10-day (May 20-May 29, 2010) time window, which is far below the seasonal climatology as well as 0.5-SD (standard deviation) departure rainfall during summer $(\tilde{X}=13 \mathrm{~mm}$, where $\tilde{X}$ is the average summer precipitation during baseline period 1970-1999) of 2010.

To understand the role of mesoscale circulation changes in the occurrence of unprecedented warm-dry events, the spatial pattern of composite vertically integrated moisture transport (IVT; refer SI 1.5 for details) is illustrated for the summer 2010's heatwave event (Figure 2b). Figure $2 \mathrm{~b}$ compares the moisture transport on $22^{\text {nd }}$ May, the day of occurrence of the heatwave (Figure $2 \mathrm{~b}$, top panel), and its surrounding days. A lack of moisture transport (IVT $<100 \mathrm{kgs}^{-1} \mathrm{~m}^{-1}$ ) is evident over a large portion of north India, encompassing the Ahmedabad city (indicated as a green circle) in Gujarat state, located on the western coast of the country during two days prior and a week after the occurrence of the extreme temperature. The maps of moisture transport show a southeastward integrated moisture flux on $20^{\text {th }}$ May (Figure $2 \mathrm{~b}$, top panel), which gradually shift towards the Bay of Bengal in the east on the day of the maximum temperature 
of $22^{\text {nd }}$ May. To further identify anomalous features of moisture transport associated with heatwave events, I present a standardized anomaly of IVT with respect to its long-term climatology (Figure 2b, bottom panel). As shown in Figure 2b (bottom panel), less-than-normal IVT anomalies are originating from Central India during $20^{\text {th }}$ and $22^{\text {nd }}$ May. On $29^{\text {th }}$ May, although IVT anomalies are above-normal over Central India, still scattered patches of anomalous hotspots of IVT are pronounced at a few locations over northwest, northeast, and southwestern regions. Overall, The IVT anomalies are intensified and concentrated on the date of occurrence of the maximum temperature (i.e., on $22^{\text {nd }}$ May), whereas those within a week of occurrence of the maximum temperature (i.e., on $29^{\text {th }}$ May), tend to become weak and scattered. Analogous to arid part of the country, I show the compound heat stress-dry spell event delineation by taking the example of Guwahati, which is located in the humid region (Figure S1). The maximum daily temperature during 2010 at Guwahati has occurred end of the month (i.e., $19^{\text {th }}$ June, 2010), which was accompanied by below-average accumulated rainfall during $17-26^{\text {th }}$ June time window and exceeded -2SD from mean seasonal (June-September) precipitation. With these illustrations, we find a clear motivation for choosing a continuous 10day period, surrounding the day of occurrence of the annual maxima daily temperature record.

Next, we investigate the seasonality of heatwaves to identify the "heatwave rich" period. Figure 3 presents the time evolution of extreme temperature over the major urban areas of the country. The annual distribution of average monthly temperature for the selected cities from various hydroclimatic regions shows a distinct pattern (Figure 3a). As observed, the time to peak the extreme temperature varies from April (in Thiruvananthapuram) to August (in Guwahati) across the climate regions. The average timing of temperature extreme (i.e., annual maxima temperature) across the cities shows a coherent pattern with the timing of heatwaves spatially varies from south to the northeast part of the country (Figure 3b).

Based on the average occurrence time of annual maxima temperature, the Indian subcontinent could be classified into four distinct zones, i.e., zone 1 includes the Peninsular India, where the average time to the maximum temperature is in April; zone $\mathbf{2}$ includes the whole of northwest, west-central and southern part of central northeast India in which the time to heatwave is during May; zone 3: covers the rest of north India in which the average time to maximum temperature is during June; zone 4: stretches across the northeast, where the average time to the maximum temperature is delayed the most and found to be in July for Guwahati city. More than $50 \%$ of stations (i.e., 13 out of 23) show average time to peak daily temperature during May (Figure $3 \mathrm{~b})$ and are located in zone 2.

Recently, Satyanarayana and Rao (2020) have identified three heatwaves zones across the country, which coincide largely with locations of zone 2 from our study. Our findings are in agreement with Satyanarayana and Rao (2020), in which authors have also detected the occurrence day of the maximum temperature over most of the regions during May. Further, the 
authors have linked the extreme HWI severity in this region to the advection of heat due to prevailing wind speed. During May and June, zones 2 and 3, remain dry and experiences extreme heatwaves till moisture arrives over these regions with the advancement of the monsoon. On the other hand, the average occurrence time of the maximum temperature over zone 1 (that includes three cities, Thiruvananthapuram, Coimbatore, and Bengaluru) could be linked to the earlier onset time of monsoon over the Kerala region as compared to the rest of the country (Stolbova et al. 2016). The difference in the spatial distribution of occurrence of extreme temperature is due to the annual path of the sun and difference in moisture distribution over the country because of the presence of two seas on either side of Peninsular India as well as the onset and propagation of monsoon over the country from June onwards (Pai et al. 2013).

\subsection{Spatial Variability in Trends among Individual Drivers}

Figure 4 maps trends of the time series of individual drivers for each site during the analysis period. A visual inspection reveals each driver is not changing uniformly and the sign and magnitude of trend vary differently for each variable, which may be affected by the periods being considered. An increasing trend in HWI is noted over $70 \%$ of sites (18 out of 23; Table S2), 8 of which are statistically significant (at $10 \%$ level). The increase (Eq. 1) in HWI ranges between 0.2 and $1.32 \%$-decade $^{-1}$ with the highest increase is observed for Kolkata (Figure S7) followed by Guwahati city (both in the northeast climatic region), which suggests cities across the northeast climatic region are warming faster as compared to the other regions. The findings of this study are in agreement with one earlier study (Matthews et al. 2017) that identified Kolkata as one of the global hotspots of extreme heatwaves that could expect conditions equivalent to 2015's deadly heat waves every year. The increasing HWI at Guwahati city shows the increased propensity of heatwaves in humid areas of the country (Im et al. 2017; Raymond et al. 2020). On the other hand, the majority of sites show a statistically significant decreasing low wind speed over more than half of the sites $(65 \% ; 15$ out of 23$)$. The rate of decrease in low wind speed varies from 9 to $36 \%$-decade ${ }^{-1}$. Moreover, according to the MannKendall trend statistics the largest significant decrease in low wind speed is observed over cities situated across eastern coastal plains of India, Visakhapatnam followed by Chennai (Figures 1a and 4; Table S2). Our result is in agreement with (Saha et al. 2017), which showed a significant decrease in summertime near-surface wind speed over the eastern coast as compared to the western coast of the country. An earlier study by (Saha et al. 2017) showed that the significant decrease in near-surface wind speed at the eastern coast could be a consequence of a decrease in atmospheric instability components - such as a decrease in Convective Available Potential Energy (CAPE), vertical wind shear, whereas an increase in lifted index.

Unlike trends in HWI and low wind speed, the trend in precipitation shows a mixed pattern with a mix of increasing and decreasing trends throughout. While the decrease in precipitation ranges from $1-8 \%$ decade $^{-1}$. While an increase in accumulated precipitation is observed in 
Raipur in Central India with a 12\% increase per decade, around 52\% (12 out of 23) sites show no changes (i.e., rate of change is reported as zero; Table S2). However, none of these sites show statistically significant increasing/decreasing trends. Though statistically insignificant, a substantial decrease in precipitation is evident across the peninsular belt comprising four southern Indian cities, Thiruvananthapuram, Coimbatore, Gadag, and Visakhapatnam, and two of the cities across eastern India, i.e., Kolkata and Ranchi (Refer Mann-Kendall trend statistics in Table S2). The downward trend in daily rainfall over the southern Peninsula and notably over the lower Indo-Gangetic plain is well documented in the literature, which is attributed to several factors (Kulkarni 2012; Kulkarni et al. 2020), some of them are the weakening monsoon circulation pattern or weakening of land-atmosphere temperature gradient, whereas the upward changes in precipitation could be because of urbanization and other land-use changes, as well as aerosols that are likely to contribute to the localized heavy rainfall occurrences (Kulkarni et al., 2020). Further, an increase in the frequency and intensity of daily rainfall in central India has been reported in the earlier studies (Sen Roy and Balling Jr 2004)(Goswami et al. 2006).

The presence of statistically significant increasing and decreasing trends among hydroclimatic drivers influencing compound heat stress-dry spells prompted us to consider nonstationary models for fitting the marginal distributions of interacting drivers.

\subsection{Linking Pair-wise Dependence between Variables and Compound Warm-Dry Spells}

Next, we demonstrate the pair-wise dependence between compound warm-dry drivers using nonparametric complete as well as tail dependence metrics, Kendall's $\tau$ and Caperaa Fougeres- Genest (CFG; Frahm et al., 2005) upper (and lower) tail- dependence coefficients (Figure 5). Figure 5a presents three pair-wise complete dependence pattern, HWI versus low wind speed, low precipitation versus low wind speed, and HWI versus low precipitation, respectively using Kendall's $\tau$ correlation, whereas Figure $5 \mathrm{~b}$ shows the upper tail dependence patterns among HWI-low wind speed, and low precipitation-HWI pairs and lower tail dependence for low precipitation-low wind speed pair. The dependence between HWI and low wind speed is positive for the majority of sites across the western half of the country (Figures 5a-b; left panel). A strong positive $\hat{\lambda}_{C F G}^{U}$ is observed for cities across the northwest, westcentral, central-northeast, and peninsular climate regions of the country. Considering total dependence, the dependence strength tends to weaken from west to east (Figure 5a, left panel) and the cities across the eastern coastal plains of the country show a negative dependence (Figure 5a; left panel). The negative dependence between HWI-versus wind speed is statistically significant for Guwahati, located in the northeast region. Among all urban sites, New Delhi situated in the northwest climatic region reports the strongest positive total as well as upper tail dependence (Kendall's $\tau=0.34 ; \hat{\lambda}_{C F G}^{U}=0.37$, pvalue $<0.05$ ), whereas Guwahati in the northeast region shows a strong negative total and upper tail dependence (Kendall's $\tau=$ $-0.27 ; \hat{\lambda}_{C F G}^{U}=-0.12$, pvalue $\left.<0.10\right)$. In particular, over the Indian subcontinent 
evapotranspiration is reported to show an increasing trend during pre-monsoon (March-May) months (Goroshi et al. 2017). Although an overall declining trend in evapotranspiration is apparent across the country, especially over the northeast region, a substantial increase over the arid (western) and semi-arid (central) parts of the country has been reported in recent years (Goroshi et al. 2017). A stronger positive correlation between HWI and low wind speed during the warm season often leads to a reduction in land evaporation (or evapotranspiration). Subsequently, as evaporation is gradually reduced, a large fraction of incoming radiation warms up the environment, leading to an accumulation of sensible heat in the atmosphere and amplification of heatwaves (Miralles et al., 2019).

Unlike spatial trends in HWI versus wind speed dependence, the spatial pattern of low precipitation-low wind speed correlation shows a different trend between complete (Kendall's $\tau$ ) and lower tail correlation ( $\hat{\lambda}_{C F G}^{L}$ ) metrics (Figure $5 \mathrm{~b}$, middle panel). While the low precipitation-low wind speed pair shows a moderate to strong negative complete correlation for around $70 \%$ (i.e., 16 out of 23) urban locations, considering their lower tail dependence more than $50 \%$ (13 out of 23) of sites show a positive tail dependence. Furthermore, considering $\hat{\lambda}_{C F G}^{L}$, only three sites show a significant negative lower tail dependence, which is apparent across Dehradun (hilly region), Hissar (northwest), and Bhubaneswar at the coast (in the central northeast region) respectively. While a faster wind speed is typically associated with more precipitation (Back and Bretherton 2005), an anticorrelation relationship between the two variables favors an increased occurrence of dry summers with high evaporative demand, amplifying the likelihood of compound warm-dry conditions.

The dependence between low precipitation and HWI is negative (Figure 5; right panel) for most of the sites (for more than $90 \%$ sites; i.e., 21 out of 23 locations in case of Kendall's $\tau$ and for $\sim 78 \%$ of sites; i.e., 18 out of 23 locations for $\hat{\lambda}_{C F G}^{U}$ ) except for Mumbai (in the westcentral region) and Bengaluru (in Peninsular region) that show (insignificant) moderate to low total positive correlations, however, a strong to moderate (significant) positive correlations at their upper tails. The strength of the positive upper tail correlation is relatively stronger for Mumbai (a port city on the Arabian Sea) with value of 0.20 (pvalue < 0.05). Earlier studies have shown that at a local scale, temperature and precipitation typically show a negative correlation during the summer (Madden and Williams 1978; Trenberth and Shea 2005; Wasko and Nathan 2019). The negative correlation of HWI versus precipitation indicates the cooccurrence of hot summers accompanied by dry spells. Hot summers together with reduced precipitation lead to reduced soil moisture, whereas, extreme heat lowers evaporative cooling. On the other hand, the positive correlation is often linked to large-scale teleconnection patterns, such as due to the effects of El Niño Southern Oscillation (ENSO) and the Indian Ocean Dipole (IOD). While the above normal sea surface temperature during the El Niño episode is associated with increased convection and local precipitation (Trenberth \& Shea, 2005), an 
increase in rainfall over western India could be a consequence of the combined influence of ENSO and IOD-induced large-scale teleconnections (Ashok et al., 2004; Singh, 2006). This is reflected in the case of Mumbai because of its location at the proximity to the Arabian Sea.

Figure S8 summarizes when successive concomitants (i.e., the pairs that show the same sign or direction) among two or more interacting pairs (i.e., HWI-low precipitation, HWI-low wind, and low wind-low precipitation) show increasing (positive) or decreasing (negative) trends. When two or more dependence pairs show analogous signs, their resulting consecutive and multivariate impacts would be more pronounced relative to a case when each of these pairs shows a disparate trend in signs. For example, extremely high temperature and severe dry spell (i.e., an apparent negative dependence between HWI and precipitation), could result in a decline in wind speed modulated by mesoscale circulation pattern (i.e., results in a negative dependence between HWI and low wind speed) as shown earlier for European summer heatwaves and dry spells of 2003 (Jiménez et al. 2011). Figures S8a-b compare the spatial distributions of concomitants of dependence pairs considering complete versus tail dependences, which shows a distinct pattern between correlation metrics. While considering the complete correlation, most sites show a concurrent negative dependence, their extremes show a large concomitance towards positive correlations over $50 \%$ of sites, suggesting extreme pairs tend to cluster together favoring large exceedances. However, in both cases, less than $40 \%$ of gauges show significant concomitants. Overall, we conclude that a credible assessment of multivariate compound extremes should consider nonlinear dependence between interacting variables, including dependencies at the tail.

\subsection{Amplifications in Compound Heat Stress-Dry Spells}

Figure 6a shows the variability of multivariate joint return periods (JRP) when each of the quantile corresponds to $T=50$-year, which indicates a $2 \%$ chance of occurrence in any given year. However, considering compound extremes, the return periods of sites tend to get lower and range between 5 and 17 years. The largest reduction in return period is observed over Gadag (located in the west-central region), which showed a significant positive upper tail correlation between HWI and low wind speed, however relatively weaker tail dependencies for the other two variable pairs. This suggests a strong correlation combined with other weakly dependent pairs could lead to an increase in compound hazard with significant impacts. Furthermore, the strong upper tail correlation between HWI and low wind speed may be due to the presence of atmospheric blocking which tends to intensify owing to the urban heat island effect and often responsible for low wind speed as well as record-breaking heatwaves in urban areas (Dong et al. 2018).

The density plot of the joint return period in Figure 6a (in inset) shows a median reduction in JRP is 9-year, which suggests for the majority of locations 50-year extreme in isolation, tends 
to become a 9-year event on average considering multiple co-occurring drivers. The spatial pattern of the density function of JRP shows a long extended tail towards the right, which is primarily due to the contribution from three sites, Hyderabad, Lucknow, and Hissar that show JRP in the range of 13 to 17 years. Figure $6 \mathrm{~b}$ shows the expected amplification of compound warm-dry spells for quantiles associated with a 50-year return period using the CDPI index. The present analysis reveals a median 6-fold increase (range of 3 to 10-fold) in the expected annual number of 50-year severe HWI events for each urban location. A more than 6-fold amplification is observed over $\sim 39 \%$ ( 9 out of 23 ) spatial locations. A large increase is concentrated over cities across arid and semi-arid parts of the country, for example, the northwest, west-central, and peninsular climate regions of India. Among the cities across the eastern corridor, Kolkata, Ranchi, and Patna show the frequency amplification in the order of 7-8, whereas Guwahati, situated in a relatively humid climate shows an amplification of the order of 5 .

A large amplification in frequency for cities across the eastern corridor could be a consequence of (significant) increasing warming trend in Kolkata (i.e., increase in HWI at a rate of $3.12^{\circ} \mathrm{C} /$ decade) and a (significant) decrease in low wind speed at Ranchi (at a rate of decrease $\sim 3 \mathrm{kmh}^{-1} /$ decade). Using observation and regional climate model experiments, (Jiménez et al. 2011) have shown that heat waves and dry-spells can modulate the surface wind speed variability, which is induced by both synoptic as well as mesoscale patterns. Further, a recent study (Gao et al. 2018) has shown a link between warming over the Indian Ocean and dampening of large-scale upward motion over the Indian continent, resulting in a potential weakening of monsoonal circulation and wind speeds over the majority of locations in India, which explains how decreasing wind speed together with an increasing dry spell in a warming climate could contribute to an increased frequency of compound warm-dry events over major urban locations of the country. Overall, the above findings reveal the nonstationary nature of interacting drivers contribute up to an 8-fold amplification in frequency for cities across the eastern corridor leading to unprecedented compound drought situations.

\section{Summary and Conclusions}

Co-occurrence or consecutive occurrence of two or more climate extremes can produce an extreme impact than either of the occurrence of extreme in isolation (AghaKouchak et al. 2014; Leonard et al. 2014). Analysis of concurrent and multivariate clustered events is crucial for precise assessment of climate-informed risk in a warming climate. Based on observational evidence, this study explores the compound warm-dry potentials in urban India through cooccurrence of heatwaves, precipitation deficit, and low wind speed and demonstrates how the hazard potential of such multivariate compound extreme would modify in a nonstationary climate. To the best of our knowledge, using high-quality gauge-based observational records, this study is the first to quantify the multivariate risk of concurrent climate extremes considering more than two climate variables covering six different hydrometeorological 
regions, especially over densely populated and highly invested urban locations of India. The strength of gauge-based observational records as compared to previous assessments (Hao et al., 2018; Ridder et al., 2020; Sharma and Mujumdar, 2017; De Luca et al., 2020; (VillalobosHerrera et al. 2020) is its ability to preserve local variabilities, although station-based records have certain limitations such as uncertainties owing to gaps in observations and sparse spatial coverage of station networks. However, in areas of complex terrain with large spatial heterogeneity, extremes are often underestimated in the gridded dataset or satellite-based products, especially for the intensity and frequency of extremes (Kandlikar et al. 2005; King et al. 2013; Timmermans et al. 2019; Raymond et al. 2020).

Based on the timing of occurrence of extreme temperature, this analysis identifies four distinct zones that show seasonal (temporal) clustering of heatwaves timing. Further, the current analysis identifies (significant) increasing trends in HWI whereas decreasing trends in nearsurface wind speed throughout. For most sites, a significant negative dependence is apparent between HWI and precipitation for complete as well as at their upper tail correlations. On the other hand, the dependence between HWI - low wind speed, and precipitation deficit - low wind speed pairs show often a mixed pattern. Also, results reveal $\sim 3$ to 10 -fold amplification in the expected annual number of 50-year events for each urban location, suggesting a 50-year event tends to become 5 to 18 -year events. To summarize, the spatial distribution of JRP and CDPI suggest accounting for correlations among interacting drivers, rarer events tend to occur more frequently in all urban locations. The above results further confirm the expected amplification of the compound extreme is sensitive to the dependence among interacting drivers as well as the presence of nonstationary trends among climate variables.

In particular, the increasingly warm summer temperature together with a precipitation deficit may lead to significantly low soil-moisture content, triggering a feedback mechanism that amplifies the persistent warm-dry conditions (Miralles et al. 2019; De Luca et al. 2020), leading to flash droughts, which evolves rapidly because of abnormally high temperature compounded by lower-than-average rainfall and winds within a limited time window (Mishra et al. 2021). Even though heatwaves and meteorological droughts (results from prolonged dry-spell) frequently span at different temporal scales, the former being typically shorter (often weeks' scale) than the latter (in months to years), the linkage between two is intuitive - as soil and vegetation dry out and there is a reduction in evapotranspiration, the air becomes drier, which further decline the likelihood of rainfall and trigger the meteorological drought occurrences (Miralles et al., 2019).

Further, heatwaves and dry spells can alter mesoscale circulations and thereby influencing soil moisture variability leading to a decrease in surface wind speed (Jiménez et al. 2011). Further, findings from this study also highlight the close connection between extreme temperature, low precipitation, and surface wind speed - a coupling of which may results in compound summer 
warm-dry events over urban areas of the Indian subcontinent. Therefore, a multivariate perspective is essential to precisely account for interaction among variables and appropriately assess their impacts to develop climate-informed adaptation strategies. The multi-hazard framework developed in this study would be helpful to calculate compound climate risks in a warming climate and further developing an impact database such as for mapping heat-health risks in urban areas, crop insurance losses, or assessing potentials for renewable power generation. Further, results from this study would provide valuable insights to assess biases in climate model simulations and to evaluate models' credibility in precisely estimating the joint behavior of compound extremes under deep uncertainties related to climate variability and change (Brown et al. 2020; Villalobos-Herrera et al. 2020). The derived insights would ensure adaptive policies to maximize urban resilience in the face of climate uncertainty.

A few caveats to be noted - in this study, stressors, such as multi-sector water demand, demographic shifts, and regulatory issues, e.g., transboundary water interactions are not considered; since these considerations are beyond the scope of the present analysis. This study emphasizes the interdependence between extreme (dry-bulb temperature) heatwave, precipitation deficit, and low wind-speed. It does not, however, include the potential impact of humid-heat controlled by wet-bulb temperature; much lower values of which can have serious health consequences, especially for cities at the proximity of coasts (Raymond et al. 2020). This further, opens up future research avenues since $~ 560$ million (comprising $14.2 \%$ of the total population) people in India is residing on coasts (CZMSB, 2011), and humid heatwaves in coastal cities located in the subtropical climate region are shown to be more intense and increasingly severe in a warming climate (Raymond et al. 2020). Further, owing to climate change, the frequency and intensity of heatwaves tend to increase in the upcoming years (Stocker 2014), which may lead to increases in human mortality, disruption in power supplies, hospitals, and emergency services in cities. The warmer temperature and scarcer available water when intersect with the COVID-19 pandemic, the concurrent crises impact the urban resilience and threaten public safety (Phillips et al. 2020). Going forward, leveraging the probabilistic framework developed in this study, an extension to a multi-hazard early warning system would aid in urban resilience in the Anthropocene.

\section{Acknowledgments}

I thank the India Meteorological Department (IMD) for providing station-based meteorological data. The work is supported through Science and Engineering Research Board, Government of India's early career start-up grant, SRG/2019/000044. The host university, the Indian Institute of Technology Kharagpur has provided partial support.

\section{Data Availability Statement}


821 Observed daily meteorological data for each urban site can be retrieved from the Data Supply 822 Portal of the IMD (http://dsp.imdpune.gov.in/). The analysis is performed in MATLAB 823 R2015a. The MATLAB scripts used for this work are available upon request from the 824 corresponding author.

825 
841

842

843

844

845

846

847

848

849

850

851

852

853

854 855

856

\section{References}

AghaKouchak A, Cheng L, Mazdiyasni O, Farahmand A (2014) Global warming and changes in risk of concurrent climate extremes: Insights from the 2014 California drought. Geophysical Research Letters 41:8847-8852

Azhar GS, Mavalankar D, Nori-Sarma A, et al (2014) Heat-Related Mortality in India: Excess All-Cause Mortality Associated with the 2010 Ahmedabad Heat Wave. PLOS ONE 9:e91831

Back LE, Bretherton CS (2005) The Relationship between Wind Speed and Precipitation in the Pacific ITCZ. Journal of Climate 18:4317-4328

Bandyopadhyay N, Bhuiyan C, Saha AK (2016) Heat waves, temperature extremes and their impacts on monsoon rainfall and meteorological drought in Gujarat, India. Natural Hazards 82:367-388

Basara JB, Basara HG, Illston BG, Crawford KC (2010) The impact of the urban heat island during an intense heat wave in Oklahoma City. Advances in Meteorology 2010:230365, DOI: $10.1155 / 2010 / 230365$

Basara JB, Christian JI, Wakefield RA, et al (2019) The evolution, propagation, and spread of flash drought in the Central United States during 2012. Environ Res Lett 14:084025

Berghuijs WR, Allen ST, Harrigan S, Kirchner JW (2019) Growing spatial scales of synchronous river flooding in Europe. Geophysical Research Letters 46:1423-1428

Brown C, Boltz F, Freeman S, et al (2020) Resilience by design: a deep uncertainty approach for water systems in a changing world. Water Security 9:100051

Buchanan MK, Oppenheimer M, Kopp RE (2017) Amplification of flood frequencies with local sea level rise and emerging flood regimes. Environ Res Lett 12:064009. DOI: 10.1088/1748-9326/aa6cb3

Burnham KP, Anderson DR (2003) Model selection and multimodel inference: a practical informationtheoretic approach. Springer Science \& Business Media

Cheng L, AghaKouchak A, Gilleland E, Katz RW (2014) Non-stationary extreme value analysis in a changing climate. Climatic change 127:353-369

Chiang F, Mazdiyasni O, AghaKouchak A (2018) Amplified warming of droughts in southern United States in observations and model simulations. Science Advances 4:eaat2380. DOI: 10.1126/sciadv.aat2380

Coles S, Bawa J, Trenner L, Dorazio P (2001) An introduction to statistical modeling of extreme values. Springer

Czajkowski J, Villarini G, Montgomery M, et al (2017) Assessing current and future freshwater flood risk from North Atlantic tropical cyclones via insurance claims. Scientific reports 7:41609

CZMSB (Centre for Coastal Zone Management and Coastal Shelter Belt) (2011) Database on Coastal States of India

Dai A (2011) Drought under global warming: a review. WIREs Clim Change 2:45-65 
871

872

873

875

876

877

De Luca P, Messori G, Faranda D, et al (2020) Compound warm-dry and cold-wet events over the Mediterranean. Earth System Dynamics 11:793-805

DESA U (2018) World Urbanization Prospects: The 2018 Revision, Key facts. New York: NY Available online at: https://population un org/wup/Publications/(Accessed December 20, 2018)

Diffenbaugh NS, Swain DL, Touma D (2015) Anthropogenic warming has increased drought risk in California. Proceedings of the National Academy of Sciences 112:3931-3936

Dong L, Mitra C, Greer S, Burt E (2018) The Dynamical Linkage of Atmospheric Blocking to Drought, Heatwave and Urban Heat Island in Southeastern US: A Multi-Scale Case Study. Atmosphere 9:33

Duffy PB, Brando P, Asner GP, Field CB (2015) Projections of future meteorological drought and wet periods in the Amazon. Proceedings of the National Academy of Sciences 112:13172-13177

Frahm G, Junker M, Schmidt R (2005) Estimating the tail-dependence coefficient: properties and pitfalls. Insurance: mathematics and Economics 37:80-100

Ganguli P, Ganguly AR (2016) Space-time trends in U.S. meteorological droughts. Journal of Hydrology: Regional Studies 8:235-259

Ganguli P, Reddy MJ (2012) Risk assessment of droughts in Gujarat using bivariate copulas. Water resources management 26:3301-3327

Gao M, Ding Y, Song S, et al (2018) Secular decrease of wind power potential in India associated with warming in the Indian Ocean. Science Advances 4:eaat5256. DOI: 10.1126/sciadv.aat5256

Genest C, Rémillard B, Beaudoin D (2009) Goodness-of-fit tests for copulas: A review and a power study. Insurance: Mathematics and economics 44:199-213

Ghanbari M, Arabi M, Obeysekera J, Sweet W (2019) A Coherent Statistical Model for Coastal Flood Frequency Analysis Under Nonstationary Sea Level Conditions. Earth's Future 7:162-177

Golechha M, Panigrahy RK (2020) COVID-19 and heatwaves: a double whammy for Indian cities. The Lancet Planetary Health 4:e315-e316

Goroshi S, Pradhan R, Singh RP, et al (2017) Trend analysis of evapotranspiration over India: Observed from long-term satellite measurements. Journal of Earth System Science 126:1-21

Goswami BN, Venugopal V, Sengupta D, et al (2006) Increasing trend of extreme rain events over India in a warming environment. Science 314:1442-1445

Grimaldi S, Serinaldi F (2006) Asymmetric copula in multivariate flood frequency analysis. Advances in Water Resources 29:1155-1167

Gringorten II (1963) A plotting rule for extreme probability paper. Journal of Geophysical Research 68:813-814

Gudmundsson L, Leonard M, Do HX, et al (2018) Observed Trends in Global Indicators of Mean and Extreme Streamflow. Geophysical Research Letters. DOI: 10.1029/2018GL079725

Haan CT (1977) Statistical methods in hydrology: Ames. IA: University, Press/Ames 
914

Habeeb D, Vargo J, Stone B (2015) Rising heat wave trends in large US cities. Natural Hazards 76:16511665

Hao Z, Hao F, Singh VP, Zhang X (2018) Changes in the severity of compound drought and hot extremes over global land areas. Environmental Research Letters 13:124022

Harrington LJ, Otto FEL, Cowan T, Hegerl GC (2019) Circulation analogues and uncertainty in the timeevolution of extreme event probabilities: evidence from the 1947 Central European heatwave. Clim Dyn 53:2229-2247

Hassan W ul, Nayak MA (2020) Global teleconnections in droughts caused by oceanic and atmospheric circulation patterns. Environ Res Lett. DOI:.10.1088/1748-9326/abc9e2

Huang S, Li P, Huang Q, et al (2017) The propagation from meteorological to hydrological drought and its potential influence factors. Journal of Hydrology 547:184-195

Im E-S, Pal JS, Eltahir EA (2017) Deadly heat waves projected in the densely populated agricultural regions of South Asia. Science Advances 3:e1603322

Janga Reddy M, Ganguli P (2012) Application of copulas for derivation of drought severity-durationfrequency curves. Hydrol Process 26:1672-1685

Jiménez PA, Vilà-Guerau de Arellano J, González-Rouco JF, et al (2011) The Effect of Heat Waves and Drought on Surface Wind Circulations in the Northeast of the Iberian Peninsula during the Summer of 2003. J Climate 24:5416-5422

Kandlikar M, Risbey J, Dessai S (2005) Representing and communicating deep uncertainty in climatechange assessments. Comptes Rendus Geoscience 337:443-455

Katz RW (2013) Statistical Methods for Nonstationary Extremes. In: AghaKouchak A, Easterling D, Hsu $\mathrm{K}$, et al. (eds) Extremes in a Changing Climate: Detection, Analysis and Uncertainty. Springer Netherlands, Dordrecht, pp 15-37

Kemter M, Merz B, Marwan N, et al (2020) Joint Trends in Flood Magnitudes and Spatial Extents Across Europe. Geophysical Research Letters 47:e2020GL087464

Khaliq MN, St-Hilaire A, Ouarda T, Bobée B (2005) Frequency analysis and temporal pattern of occurrences of southern Quebec heatwaves. International Journal of Climatology: A Journal of the Royal Meteorological Society 25:485-504

King AD, Alexander LV, Donat MG (2013) The efficacy of using gridded data to examine extreme rainfall characteristics: a case study for Australia. International Journal of Climatology 33:2376-2387

Koster RD, Schubert SD, Suarez MJ (2009) Analyzing the Concurrence of Meteorological Droughts and Warm Periods, with Implications for the Determination of Evaporative Regime. J Climate 22:3331-3341

Kulkarni A (2012) Weakening of Indian summer monsoon rainfall in warming environment. Theor Appl Climatol 109:447-459 
Kulkarni A, Sabin TP, Chowdary JS, et al (2020) Precipitation Changes in India. In: Krishnan R, Sanjay J, Gnanaseelan C, et al. (eds) Assessment of Climate Change over the Indian Region: A Report of the Ministry of Earth Sciences (MoES), Government of India. Springer, Singapore, pp 47-72

Kumar MD (2014) Thirsty Cities: How Indian Cities Can Meet their Water Needs. Oxford University Press

Laaha G, Blöschl G (2006) Seasonality indices for regionalizing low flows. Hydrological Processes: An International Journal 20:3851-3878

Lemonsu A, Viguié V, Daniel M, Masson V (2015) Vulnerability to heat waves: Impact of urban expansion scenarios on urban heat island and heat stress in Paris (France). Urban Climate 14:586-605

Leonard M, Westra S, Phatak A, et al (2014) A compound event framework for understanding extreme impacts. Wiley Interdisciplinary Reviews: Climate Change 5:113-128

Li M, Yao Y, Luo D, Zhong L (2019) The Linkage of the Large-Scale Circulation Pattern to a Long-Lived Heatwave over Mideastern China in 2018. Atmosphere 10:89

Liu J, Niyogi D (2019) Meta-analysis of urbanization impact on rainfall modification. Scientific Reports 9:7301

Luan X, Vico G (2021) Canopy temperature and heat stress are increased by compound high air temperature and water stress and reduced by irrigation - a modeling analysis. Hydrology and Earth System Sciences 25:1411-1423

Madden RA, Williams J (1978) The Correlation between Temperature and Precipitation in the United States and Europe. Monthly Weather Review 106:142-147

Manning C, Widmann M, Bevacqua E, et al (2018) Soil Moisture Drought in Europe: A Compound Event of Precipitation and Potential Evapotranspiration on Multiple Timescales. Journal of Hydrometeorology 1255-1271. DOI: 10.1175/JHM-D-18-0017.1

Mannshardt-Shamseldin EC, Smith RL, Sain SR, et al (2010) Downscaling extremes: A comparison of extreme value distributions in point-source and gridded precipitation data. Ann Appl Stat 4:484502

Martinez-Villalobos C, Neelin JD (2019) Why Do Precipitation Intensities Tend to Follow Gamma Distributions? Journal of the Atmospheric Sciences 76:3611-3631

Martins ES, Stedinger JR (2000) Generalized maximum-likelihood generalized extreme-value quantile estimators for hydrologic data. Water Resources Research 36:737-744

Masud MB, Khaliq MN, Wheater HS (2015) Analysis of meteorological droughts for the Saskatchewan River Basin using univariate and bivariate approaches. Journal of Hydrology 522:452-466

Matthews TK, Wilby RL, Murphy C (2017) Communicating the deadly consequences of global warming for human heat stress. Proceedings of the National Academy of Sciences 114:3861-3866

Mazdiyasni O, AghaKouchak A, Davis SJ, et al (2017) Increasing probability of mortality during Indian heat waves. Science Advances 3:e1700066 
Mazdiyasni O, Sadegh M, Chiang F, AghaKouchak A (2019) Heat wave intensity duration frequency curve: A multivariate approach for hazard and attribution analysis. Scientific reports 9:1-8

McGee M (2018) Case for omitting tied observations in the two-sample t-test and the Wilcoxon-MannWhitney Test. PloS one 13:e0200837

Min K-H, Chung C-H, Bae J-H, Cha D-H (2020) Synoptic characteristics of extreme heatwaves over the Korean Peninsula based on ERA Interim reanalysis data. International Journal of Climatology 40:3179-3195

Mirakbari M, Ganji A, Fallah SR (2010) Regional bivariate frequency analysis of meteorological droughts. Journal of Hydrologic Engineering 15:985-1000

Miralles DG, Gentine P, Seneviratne SI, Teuling AJ (2019) Land-atmospheric feedbacks during droughts and heatwaves: state of the science and current challenges. Annals of the New York Academy of Sciences 1436:19-35

Mishra V, Aadhar S, Mahto SS (2021) Anthropogenic warming and intraseasonal summer monsoon variability amplify the risk of future flash droughts in India. npj Clim Atmos Sci 4:1-10

Mora C, Spirandelli D, Franklin EC, et al (2018) Broad threat to humanity from cumulative climate hazards intensified by greenhouse gas emissions. Nature Climate Change 8:1062

Nguyen VD, Metin AD, Alfieri L, et al (2020) Biases in national and continental flood risk assessments by ignoring spatial dependence. Scientific Reports 10:19387

Pai DS, Nair SA, Ramanathan AN (2013) Long term climatology and trends of heat waves over India during the recent 50 years (1961-2010). Mausam 64:585-604

Pérez-Sánchez J, Senent-Aparicio J (2018) Analysis of meteorological droughts and dry spells in semiarid regions: a comparative analysis of probability distribution functions in the Segura Basin (SE Spain). Theor Appl Climatol 133:1061-1074

Perkins-Kirkpatrick SE, Lewis SC (2020) Increasing trends in regional heatwaves. Nature Communications $11: 3357$

Phillips CA, Caldas A, Cleetus R, et al (2020) Compound climate risks in the COVID-19 pandemic. Nature Climate Change 10:586-588

Poulin A, Huard D, Favre A-C, Pugin S (2007) Importance of tail dependence in bivariate frequency analysis. Journal of Hydrologic Engineering 12:394-403

Ray B, Shaw R (2019) Urban Drought: Emerging Water Challenges in Asia. Springer

Raymond C, Matthews T, Horton RM (2020) The emergence of heat and humidity too severe for human tolerance. Science Advances 6:eaaw1838

Reddy MJ, Ganguli P (2013) Spatio-temporal analysis and derivation of copula-based intensity-areafrequency curves for droughts in western Rajasthan (India). Stoch Environ Res Risk Assess 27:1975-1989 
Renard B, Sun X, Lang M (2013) Bayesian methods for non-stationary extreme value analysis. In: Extremes in a Changing Climate. Springer, pp 39-95

Ribeiro AFS, Russo A, Gouveia CM, et al (2020) Risk of crop failure due to compound dry and hot extremes estimated with nested copulas. Biogeosciences 17:4815-4830

Ridder NN, Pitman AJ, Westra S, et al (2020) Global hotspots for the occurrence of compound events. Nature Communications 11:5956

Roderick ML, Hobbins MT, Farquhar GD (2009) Pan Evaporation Trends and the Terrestrial Water Balance. II. Energy Balance and Interpretation. Geography Compass 3:761-780

Rowe ST, Villarini G (2013) Flooding associated with predecessor rain events over the Midwest United States. Environmental Research Letters 8:024007

Saha U, Chakraborty R, Maitra A, Singh AK (2017) East-west coastal asymmetry in the summertime near surface wind speed and its projected change in future climate over the Indian region. Global and Planetary Change 152:76-87

Salvadori G, Durante F, Michele CD (2013) Multivariate return period calculation via survival functions. Water Resources Research 49:2308-2311

Sato T, Nakamura T (2019) Intensification of hot Eurasian summers by climate change and landatmosphere interactions. Scientific Reports 9:10866

Satyanarayana GCH, Rao DB (2020) Phenology of heat waves over India. Atmospheric Research 105078

Schewe J, Heinke J, Gerten D, et al (2014) Multimodel assessment of water scarcity under climate change. Proceedings of the National Academy of Sciences 111:3245-3250

Schiermeier Q (2014) Water risk as world warms. Nature News 505:10. DOI: 10.1038/505010a

Schumacher DL, Keune J, van Heerwaarden CC, et al (2019) Amplification of mega-heatwaves through heat torrents fuelled by upwind drought. Nature Geoscience 12:712-717

Sen Roy S, Balling Jr RC (2004) Trends in extreme daily precipitation indices in India. International Journal of Climatology: A Journal of the Royal Meteorological Society 24:457-466

Sharma S, Mujumdar P (2017) Increasing frequency and spatial extent of concurrent meteorological droughts and heatwaves in India. Scientific Reports 7:15582

Shastri H, Barik B, Ghosh S, et al (2017) Flip flop of Day-night and Summer-Winter Surface Urban Heat Island Intensity in India. Scientific Reports 7:40178

Shiru MS, Shahid S, Chung E-S, Alias N (2019) Changing characteristics of meteorological droughts in Nigeria during 1901-2010. Atmospheric Research 223:60-73

Singh J, Vittal H, Karmakar S, et al (2016) Urbanization causes nonstationarity in Indian Summer Monsoon Rainfall extremes. Geophysical Research Letters 43:11,269-11,277.

Sklar A (1973) Random variables, joint distribution functions, and copulas. Kybernetika 9:449-460 
1035

1036

1037

1038

1039

1040

1041

1042

1043

1044

1045

1046

1047

1048

1049

1050

1051

1052

1053

1054

1055

1056

1057

1058

1059

1060

1061

1062

1063

1064

1065

1066

1067

1068

Stocker TF (2014) Climate change 2013: the physical science basis: Working Group I contribution to the Fifth assessment report of the Intergovernmental Panel on Climate Change. Cambridge University Press

Stolbova V, Surovyatkina E, Bookhagen B, Kurths J (2016) Tipping elements of the Indian monsoon: Prediction of onset and withdrawal. Geophysical Research Letters 43:3982-3990

Tebaldi C, Strauss BH, Zervas CE (2012) Modelling sea level rise impacts on storm surges along US coasts. Environmental Research Letters 7:014032

Teuling AJ, Loon AFV, Seneviratne SI, et al (2013) Evapotranspiration amplifies European summer drought. Geophysical Research Letters 40:2071-2075

Timmermans B, Wehner M, Cooley D, et al (2019) An evaluation of the consistency of extremes in gridded precipitation data sets. Clim Dyn 52:6651-6670

Trenberth KE, Shea DJ (2005) Relationships between precipitation and surface temperature. Geophysical Research Letters 32. DOI: 10.1029/2005GL022760

Turner SW, Nelson K, Voisin N, et al (2021) A multi-reservoir model for projecting drought impacts on thermoelectric disruption risk across the Texas power grid. Energy 231:120892

Van Loon AF (2015) Hydrological drought explained. WIREs Water 2:359-392

Villalobos-Herrera R, Bevacqua E, Ribeiro AFS, et al (2020) Towards a compound event-oriented climate model evaluation: A decomposition of the underlying biases in multivariate fire and heat stress hazards. Natural Hazards and Earth System Sciences Discussions 1-31

Wan H, Zhang X, Barrow EM (2005) Stochastic modelling of daily precipitation for Canada. AtmosphereOcean 43:23-32

Wasko C, Nathan R (2019) The local dependency of precipitation on historical changes in temperature. Climatic Change 156:105-120

Wasserstein RL, Lazar NA (2016) The ASA Statement on p-Values: Context, Process, and Purpose. The American Statistician 70:129-133

Weiss A, Hays CJ (2005) Calculating daily mean air temperatures by different methods: implications from a non-linear algorithm. Agricultural and Forest Meteorology 128:57-65

Yang J, Hu L, Wang C (2019) Population dynamics modify urban residents' exposure to extreme temperatures across the United States. Science Advances 5:eaay3452

Yang Y, McVicar TR, Donohue RJ, et al (2017) Lags in hydrologic recovery following an extreme drought: Assessing the roles of climate and catchment characteristics. Water Resources Research 53:48214837

Ye H, Fetzer EJ (2019) Asymmetrical Shift Toward Longer Dry Spells Associated with Warming Temperatures During Russian Summers. Geophysical Research Letters 46:11455-11462. 
1069 Zeevi A, Mashal R (2002) Beyond correlation: Extreme co-movements between financial assets.

1070

1071 Columbia University Technical Report, available at: https://www0.gsb.columbia.edu/faculty/azeevi/PAPERS/BeyondCorrelation.pdf.

1072 Zscheischler J, Martius O, Westra S, et al (2020) A typology of compound weather and climate events. $1073 \quad$ Nature reviews earth \& environment 1:333-347

1074 Zscheischler J, Seneviratne SI (2017) Dependence of drivers affects risks associated with compound events. $1075 \quad$ Science Advances 3:e1700263

1076

1077

1078

1079

1080

1081

1082

1083

1084 

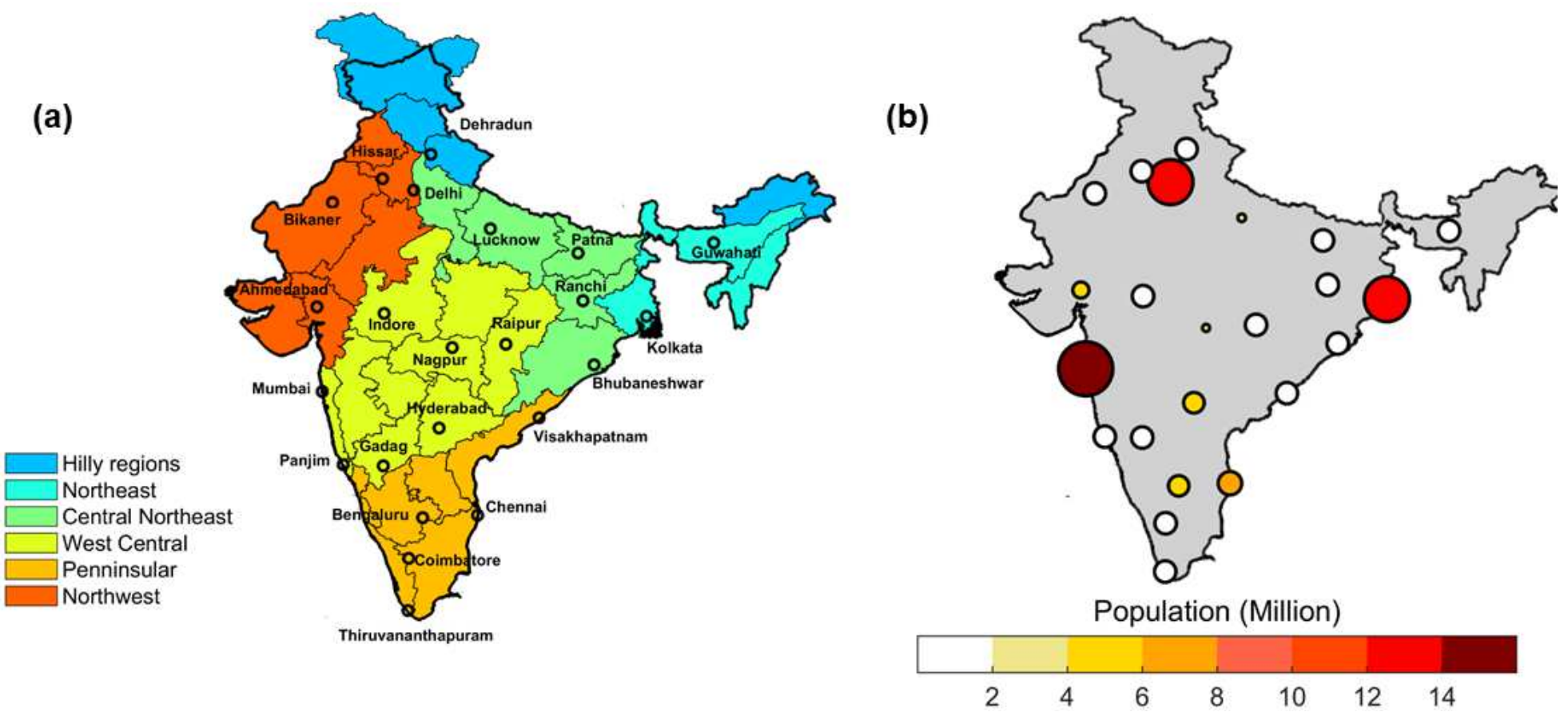

Figure 1. Locations of 23 urban areas. (a) Spatial distribution of cities across six homogeneous climate regions of the country. (b) Population distributions over these locations. 
(a)

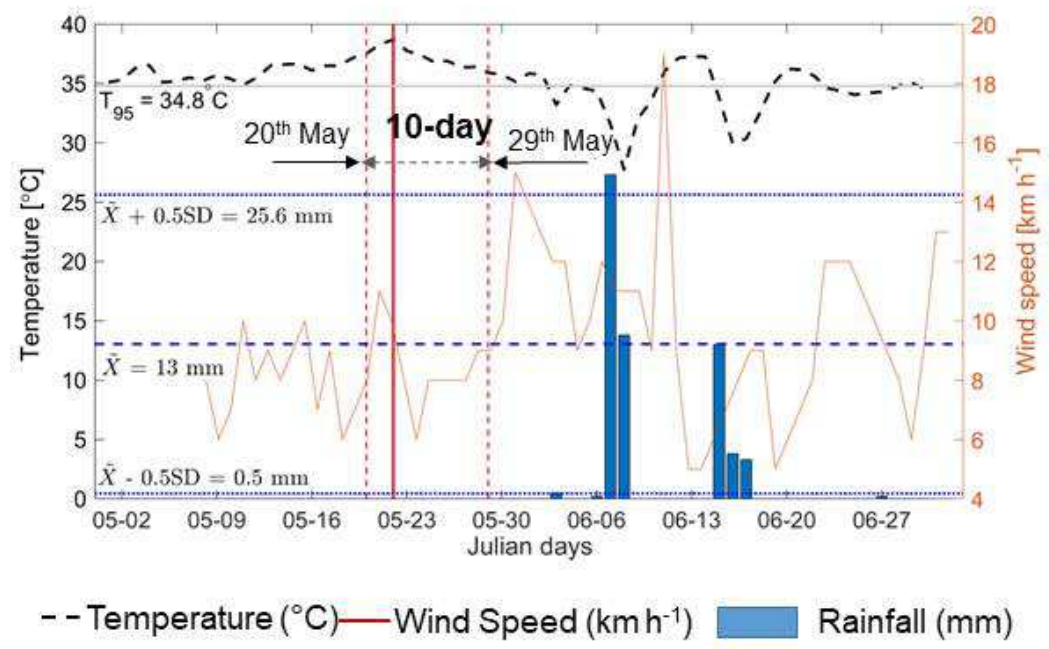

(b)
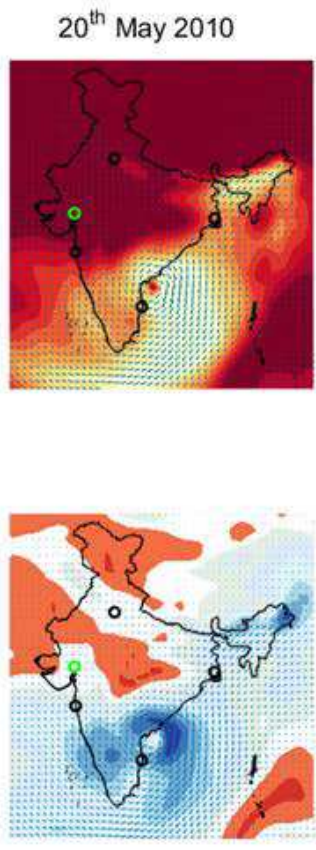

$22^{\text {nd }}$ May 2010

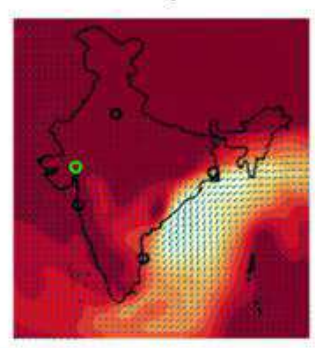

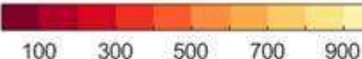
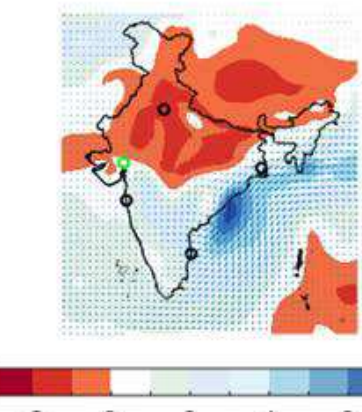

$29^{\text {th }}$ May 2010

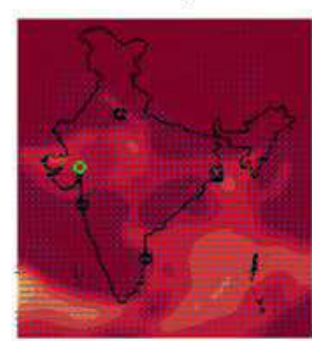

$\operatorname{IVT}\left[\mathrm{kg} \mathrm{s}^{-1} \mathrm{~m}^{-1}\right]$

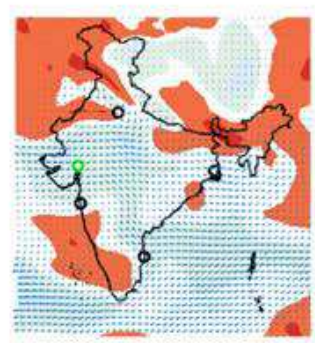

IVT Anomaly

Figure 2. Evolution of heatwaves. (a) Illustration of heatwaves characterization from daily maximum average temperature considering 2010's Gujarat (station: Ahmedabad) heatwave as an example. The line in brown shows the low wind speed; and histograms in blue shows the daily precipitation variability. The dashed horizontal line in gray (shown as $\mathrm{T}_{95}$ ) parallel to $\mathrm{x}$-axes shows the long-term $95^{\text {th }}$ percentile daily average temperature value considering the period 1970-2017 as a reference. The daily maximum average temperature during the period of heatwaves (i.e., between $20^{\text {th }}$ May and $29^{\text {th }}$ May) is consistently higher than the $\mathrm{T}_{95}$. The two dashed vertical lines denote the temporal bounds herein chosen to define the heatwave event. The horizontal dashed line (parallel to x-axes) in blue shows seasonal climatology of summer (March - May) precipitation. $\tilde{X}+0.5 S D$ and $\tilde{X}-0.5 S D$ show the upper and lower bounds of 0.5-SD (standard deviation) departure from the normal rainfall during the summer. (b) Composite of (upper panel) vertically integrated water vapor transport (IVT) and their (bottom panel) anomalies at the $0^{\text {th }}$ hour with respect to 0:00 UTC during heatwave days. The vector length is proportional to the magnitude of IVT; the vector direction indicates the direction of integrated moisture flux. The green circle show Ahmedabad city, while circles in black denote the four metropolitan cities, Delhi, Mumbai, Kolkata and Chennai respectively. 
(a)

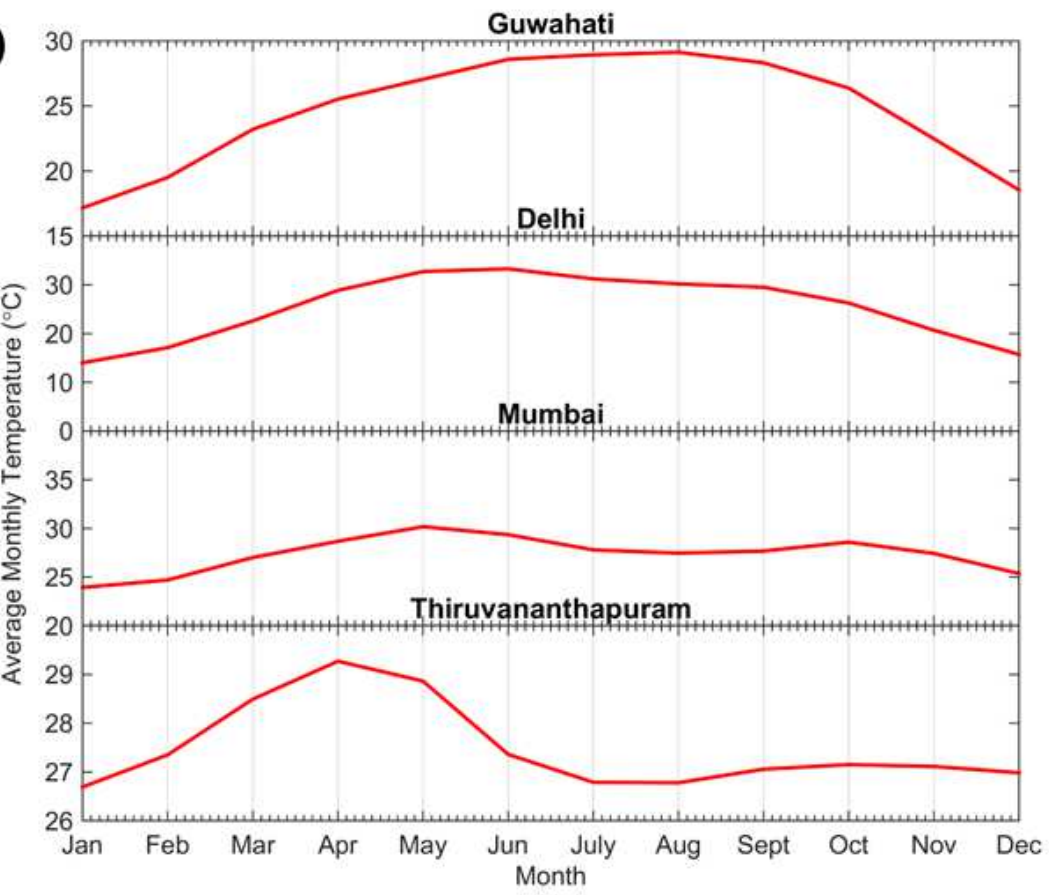

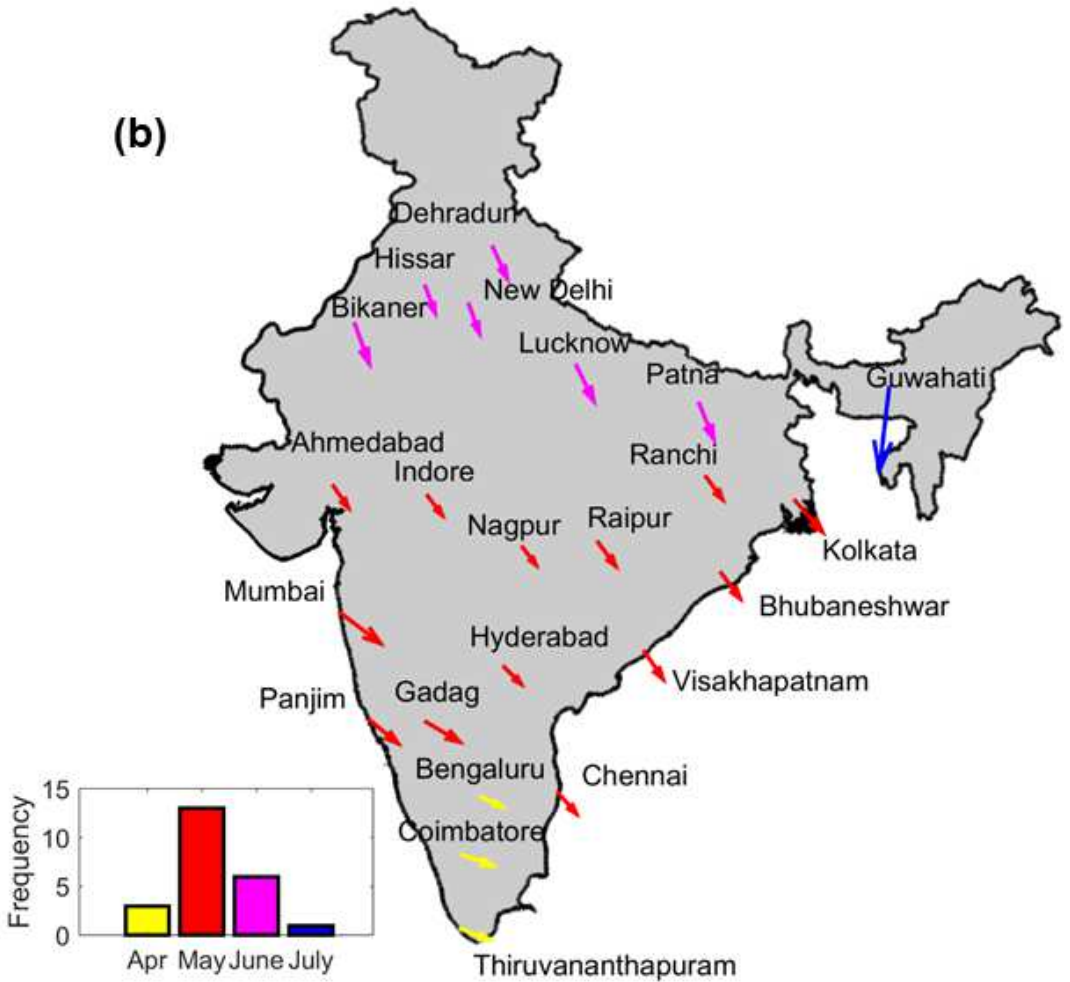

Figure 3. Illustration of the average timing of heat stress. (a) Temporal evolution of annual average temperature $\left({ }^{\circ} \mathrm{C}\right)$ over selected urban sites. (b) Spatial coherency in annual maximum (average) daily temperature. The length of the arrow indicates the variability in the timing of extreme temperature, whereas the shade shows the time of occurrence as reflected in the frequency histogram at the inset. The direction of arrows (in degrees) denotes the mean direction involving temporal periods, i.e., the day of occurrence of the extreme temperature. 


\section{Heatwave Intensity}

(a)

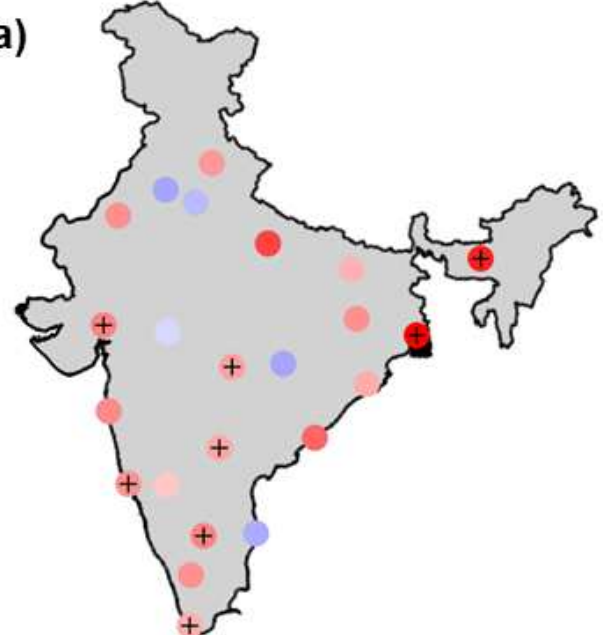

$\%$-change decade ${ }^{-1}$ (b)

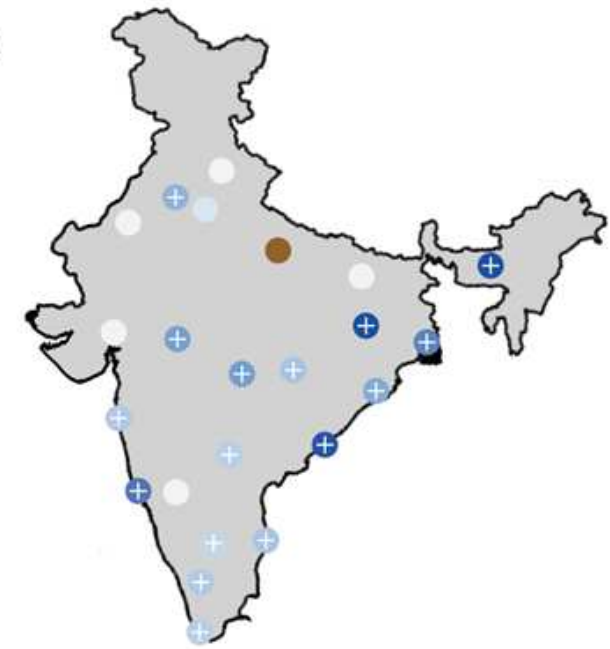

Precipitation

(c)

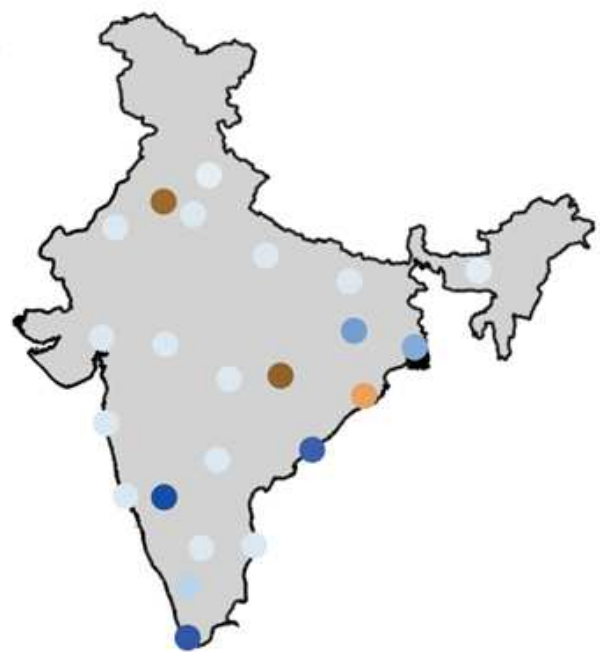

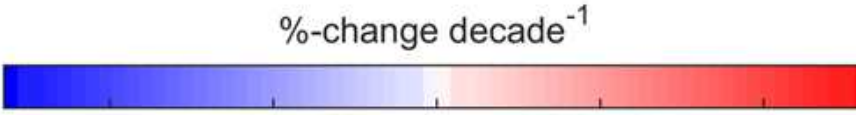

$-1$ $-0.5$ 0.5 1

$\%$-change decade ${ }^{-1}$

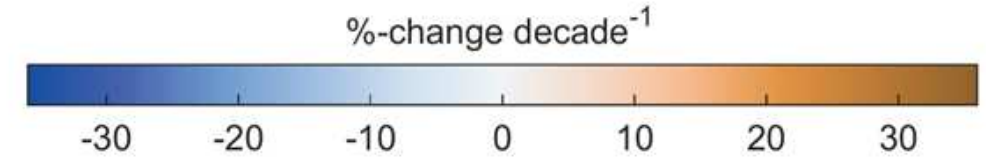

Figure 4. Trends in drivers of compound warm-dry spell. The trends in compound drought drivers (left panel) heatwave intensity $\left({ }^{\circ} \mathrm{C}\right)$; (middle panel) low wind speed $\left(\mathrm{km} \mathrm{h}^{-1}\right)$; and $(\mathrm{c})$ precipitation deficit $(\mathrm{mm})$. The shades of the circles in blue indicate a decreasing trend, whereas the shades of brown and red denote an increasing trend. The sites with a significant trend (at $10 \%$ significance level) are marked with '+'. 
(a)

HWI - Wind speed: $\lambda_{U}$

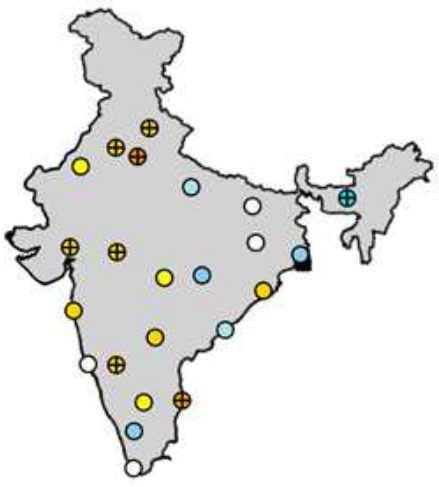

(b)

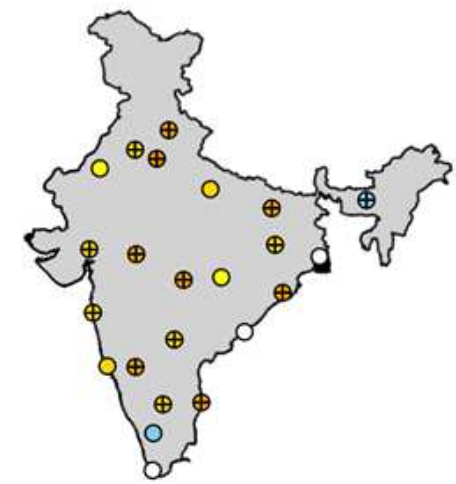

Precipitation - Wind speed: $\lambda_{L}$
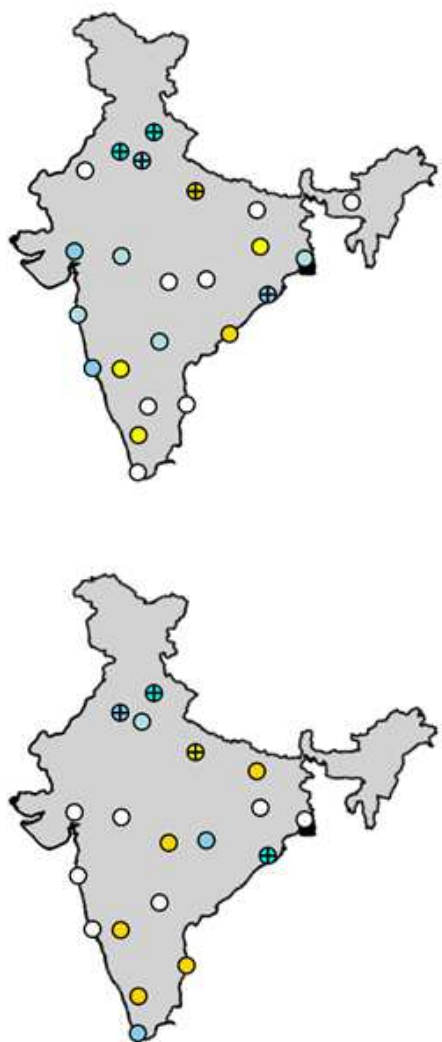

Dependence Strength
Precipitation - HWI : $\lambda_{U}$
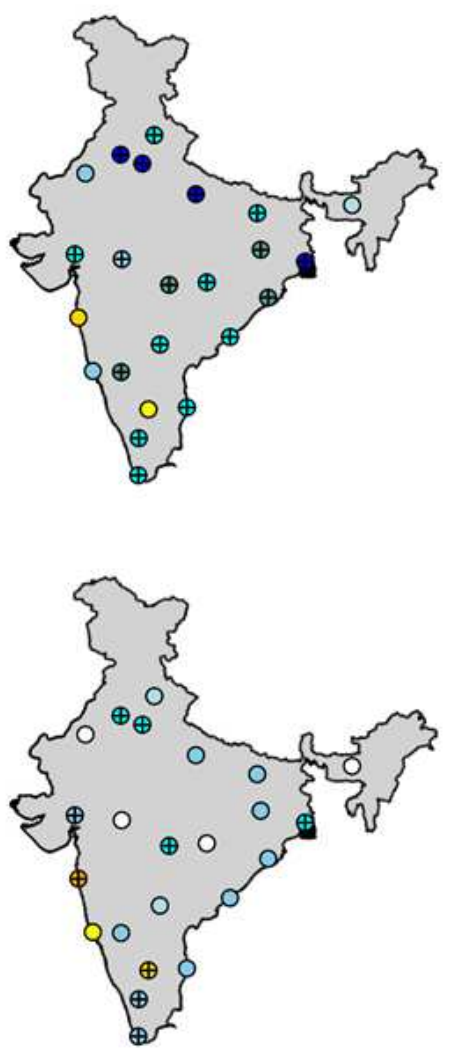

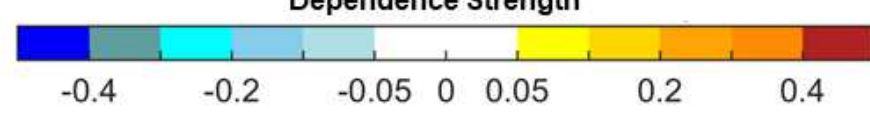

Figure 5. Dependency between drivers of compound warm-dry spell. (a) The complete versus (b) the tail dependence between (left panel) HWIlow wind speed, (middle panel) dry spell (indicated by deficit precipitation) - low wind speed, and (right panel) dry spell - HWI pairs. For the pairs, HWI-low wind speed, HWI-dry spell, the spatial variability of empirical upper tail dependence, $\lambda_{\mathrm{U}}$ is shown, whereas for the pair dry-spell versus low wind speed distribution of lower tail dependency, $\lambda_{\mathrm{L}}$ is shown. The shades in blue indicate negative dependence whereas in red show positive dependence. The sites with a significant trend (at 10\% significance level) are marked with '+'. 


\section{(a)}

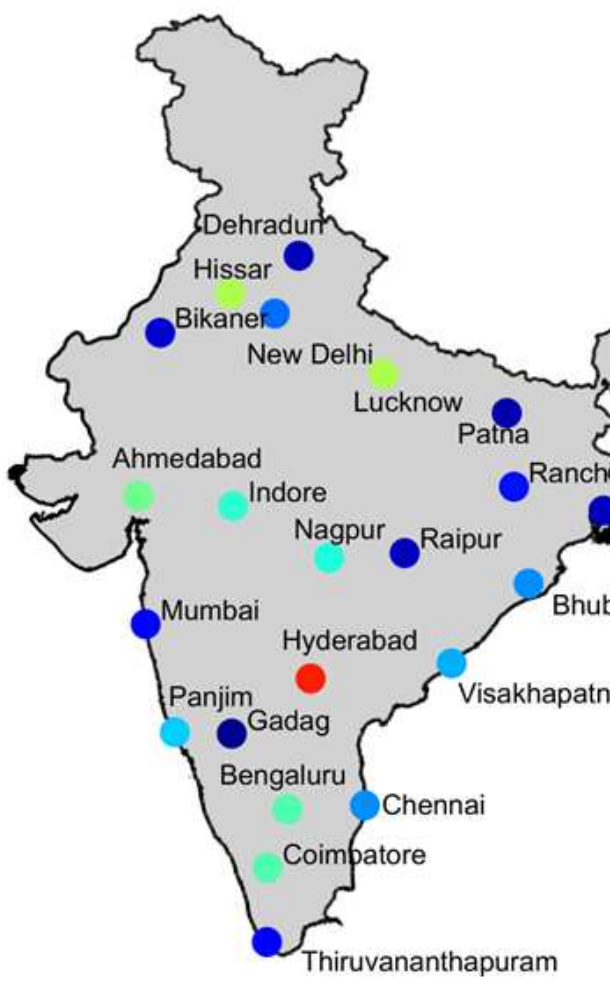

Joint Return Period (years) (b)

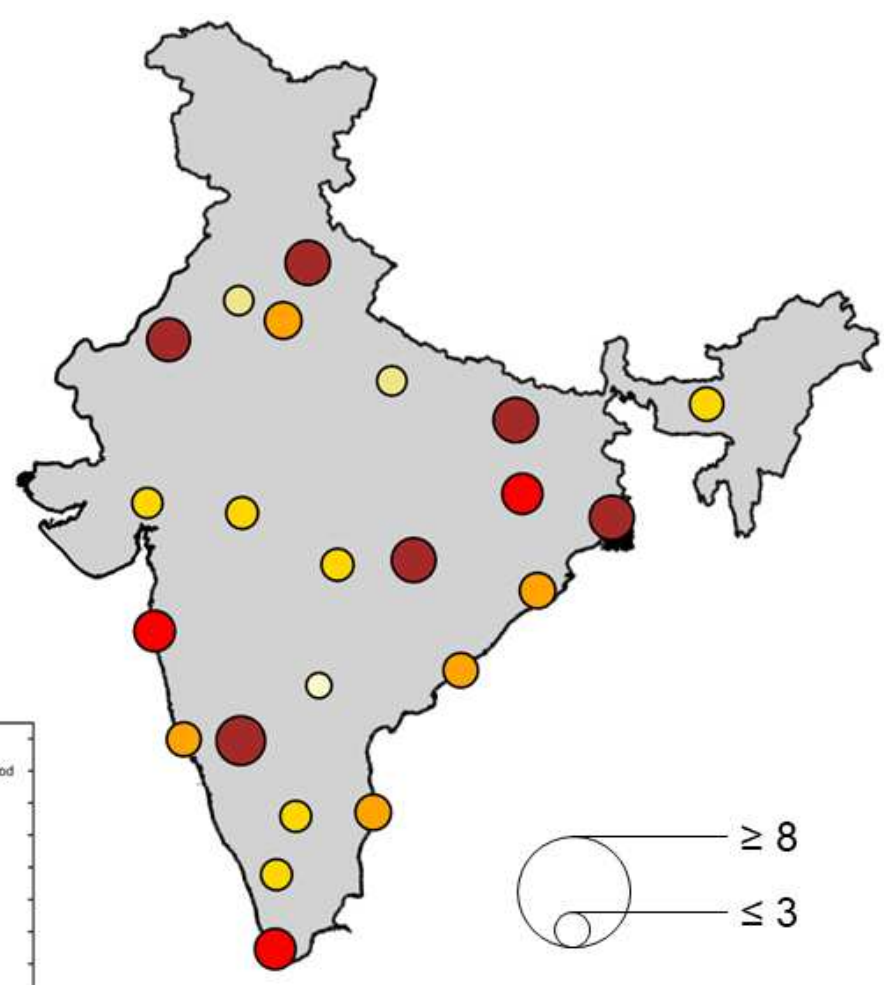

Frequency Amplification

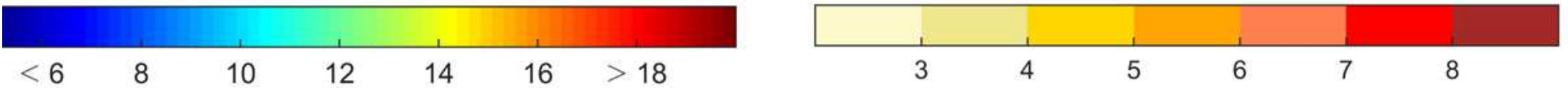

Figure 6. Amplification of compound drought frequency. (a) Map of joint return periods considering concurrence of all three drivers corresponds to at-site $T=50$-year return events influencing heatwave-induced compound warm-dry spell. The shades of circles in blue show lower return periods, indicating a more frequent occurrence of compound warm-dry events, whereas the circles in red denote higher return periods. Kernel density function showing the distribution of joint return periods over space illustrating the positive skewness (in inset). The vertical dashed line show the median joint return period. (b) Map of CDPI showing amplifications in compound warm-dry spell over urban locations. The smaller size of the circle with lighter shade indicates lower frequency amplification, whereas, the larger size of a circle with darker shade shows larger amplification of frequency, which indicates higher hazard potential of the concurrent event. 


\section{Supplementary Files}

This is a list of supplementary files associated with this preprint. Click to download.

- Supportinglnformation.pdf 